\title{
Gene markers of cellular aging in human multipotent stromal cells in culture
}

Ian H Bellayr ${ }^{1}$, Jennifer G Catalano ${ }^{1}$, Samir Lababidi², Amy X Yang ${ }^{1}$, Jessica L Lo Surdo ${ }^{3}$, Steven R Bauer ${ }^{3}$ and Raj K Puri ${ }^{* *}$

\begin{abstract}
Introduction: Human multipotent stromal cells (MSCs) isolated from bone marrow or other tissue sources have great potential to treat a wide range of injuries and disorders in the field of regenerative medicine and tissue engineering. In particular, MSCs have inherent characteristics to suppress the immune system and are being studied in clinical studies to prevent graft-versus-host disease. MSCs can be expanded in vitro and have potential for differentiation into multiple cell lineages. However, the impact of cell passaging on gene expression and function of the cells has not been determined.
\end{abstract}

Methods: Commercially available human MSCs derived from bone marrow from six different donors, grown under identical culture conditions and harvested at cell passages 3, 5, and 7, were analyzed with gene-expression profiling by using microarray technology.

Results: The phenotype of these cells did not change as reported previously; however, a statistical analysis revealed a set of 78 significant genes that were distinguishable in expression between passages 3 and 7 . None of these significant genes corresponded to the markers established by the International Society for Cellular Therapy (ISCT) for MSC identification. When the significant gene lists were analyzed through pathway analysis, these genes were involved in the top-scoring networks of cellular growth and proliferation and cellular development. A meta-analysis of the literature for significant genes revealed that the MSCs seem to be undergoing differentiation into a senescent cell type when cultured extensively. Consistent with the differences in gene expression at passage 3 and 7, MSCs exhibited a significantly greater potential for cell division at passage 3 in comparison to passage 7.

Conclusions: Our results identified specific gene markers that distinguish aging MSCs grown in cell culture. Confirmatory studies are needed to correlate these molecular markers with biologic attributes that may facilitate the development of assays to test the quality of MSCs before clinical use.

\section{Introduction}

Multipotent stromal cells, also defined as mesenchymal stem cells (MSCs), undergo sustained growth in vitro and can give rise to cells of multiple lineages, such as adipocytes, chondrocytes, and osteoblasts [1-3]. MSCbased therapies hold potential in the field of regenerative medicine by combining elements of tissue engineering and immunosuppression to treat indications of human disorders, such as organ failure, traumatic limb injuries, genetic disorders, graft-versus-host disease, cardiovascular

\footnotetext{
* Correspondence: raj.puri@fda.hhs.gov

${ }^{1}$ Tumor Vaccines and Biotechnology Branch, Division of Cellular and Gene Therapies, Center for Biologics and Evaluation Research, US Food and Drug Administration, Bethesda, MD, USA

Full list of author information is available at the end of the article
}

disease, and autoimmune disease. Hundreds of clinical trials are actively recruiting patients with specific ailments to investigate the safety and efficacy of MSCs $[4,5]$.

MSCs can be isolated from a number of different tissues, including adipose, dermis, skeletal muscle, menstrual blood, and umbilical cord blood, but are most notably derived from bone marrow [6-12]. According to a consensus of the International Society of Cellular Therapy (ISCT), MSCs have been classified by the common characteristics of (a) adherence to plastic in standard cell-culture conditions; (b) combination of positive and negative expression of cell-surface markers (CD105+, CD73+, CD90+, CD45-, CD34-, CD14-, CD11b-, CD79 $\alpha$, CD19-, and HLA-DR); and (c) In vitro differentiation into 
osteoblasts, chondrocytes, and adipocytes, as demonstrated by cell-culture staining [13]. Classification of MSCs has been further explored in the areas of additional phenotypic expression markers (CD29+, CD166+, CD133-), the benefits of immunomodulation, and precursory differentiation of cells along the ectoderm and endoderm lineage, as well as their isolation from different tissue sources [14-19].

As a heterogeneous population, MSCs have made product characterization a challenging task for investigators. The heterogeneous population of MSCs is most likely the result of contaminating cells because of the variability in isolation methods and culturing procedures, which can greatly influence their phenotype. Attempts have been made to reduce heterogeneity through separation of cells by adhesion characteristics, flow cytometry, or immunomagnetic separation [20-22]. Several studies have found that MSCs isolated from different tissue sources, including bone marrow, adipose tissue, and umbilical cord blood, have varying gene-expression profiles, which results in different trilineage cell-differentiated outcomes [23-25]. Furthermore, variation in the behavior of MSCs isolated from the same tissue sources are observed for different donors [26-30].

For some cell applications, MSC passaging and expansion in cell culture is necessary to generate sufficient numbers for transplantation. It is not clear what impact extensive cellular passaging and expansion have on the biologic activity of MSCs and in their clinical use. It has been reported that MSC populations become more homogeneous with serial passaging; however, this leads to senescent cell behavior and an impaired capacity for multipotent differentiation [31,32]. Additionally, increases in cell size and telomere shortening are commonly associated with aging cells in culture [33-36]. Other variables such as the donors' age, body mass, gender, environment, and medical history may have a profound impact on a population of MSCs for a given therapeutic use $[37,38]$. These confounding variables indicate the necessity of markers that aid in rapid prediction of MSC quality and safety for a desired function. The present work aims to identify potentially predictive gene markers of human bone marrow-derived MSCs indicating cell aging through two-color gene-expression microarray technology. We hypothesize that specific gene markers exist that will distinguish aging MSCs grown in cell culture.

\section{Methods}

\section{Cultivation and expansion of human bone marrow- derived MSCs}

Human MSCs from six different donors were purchased from ALLCELLS and Lonza (Table 1). Because these cells were commercially available, no patient consent or
Table 1 Donor characteristics and cell passage

\begin{tabular}{cccccc}
\hline Number & Donor & Sex & Age & Passages & Company \\
\hline 1 & PCBM1641 & M & 23 & $3,5,7$ & ALLCELLS \\
2 & PCBM1632 & F & 24 & $3,5,7$ & ALLCELLS \\
3 & 167696 & $F$ & 22 & $3,5,7$ & Lonza \\
4 & 110877 & $\mathrm{M}$ & 22 & $3,5,7$ & Lonza \\
5 & $8 \mathrm{~F} 3560$ & $\mathrm{~F}$ & 24 & $3,5,7$ & Lonza \\
6 & PCBM1662 & $\mathrm{F}$ & 31 & $3,5,7$ & ALLCELLS \\
\hline
\end{tabular}

approval from the FDA Research Involving Human Subject Committee was needed. Flow-cytometry analysis provided from each company revealed a marker profile of CD29+, CD44+, CD105+, CD166+, CD14-, CD34-, and CD45- for each donors' MSCs. Cell viability was greater than $85 \%$ for all donors. MSCs were cultured in expansion medium containing $\alpha$ MEM (alpha minimum essential media) (Life Technologies, Grand Island, NY), 10\% FBS (fetal bovine serum) (JM Bioscience, San Diego, CA), 1\% L-glutamine (Life Technologies), and 1\% penicillin $\mathrm{G}$ and streptomycin (Life Technologies) under a humidified atmosphere of $5 \% \mathrm{CO}_{2}$ at $37^{\circ} \mathrm{C}$, according to Lo Surdo et al. [39]. After reaching $80 \%$ confluence, cells were detached from the flask by using $0.25 \%$ trypsin/ $1 \mathrm{~m} M$ EDTA solution (Life Technologies) and replated at a density of 60 cells $/ \mathrm{cm}^{2}$. The cells were expanded until the end of the seventh passage and snap frozen after passages 3,5 , and 7.

\section{Sample preparation: RNA isolation}

Total RNA isolation was performed for the six donors at passages 3, 5, and 7 (18 different samples) by using the Qiagen RNeasy Mini Kit as per the manufacturer's instructions. RNA quality was analyzed with the Agilent 2100 bioanalyzer if the average RNA integrity value (RIN) was $9.9 \pm 0.16$. The RNA concentration was measured by using the Nanodrop 1000 spectrophotometer.

\section{Microarray hybridization}

Microarrays were produced containing 35,035 70-mer oligonucleotide probes that represented 25,100 unique genes and 37,632 transcripts, as previously described [40]. All slides were produced in our laboratory and quality tested.

Total RNA from each donor at each passage $(5 \mu \mathrm{g})$ was reverse transcribed to the corresponding CDNA, as previously described [41]. The reference material for the arrays was composed of equal quantities of reversetranscribed passage 3 RNA from donors 1 through 6 . Sample cDNA and reference materials were labeled with Hyper5 and Cy3 reactive dye (GE Healthcare, Piscataway, NJ), respectively, in $0.1 M$ sodium bicarbonate, $\mathrm{pH}$ 9.1, in the dark for 1.5 hours. After purification by MinElute column, Hyper5- and Cy3-labeled cDNA were combined and mixed with the hybridization solution 
(Life Technologies). The combined cDNA/hybridization solution was pipetted over the entire surface of the slide and hybridized overnight ( 16 hours) at $42^{\circ} \mathrm{C}$ with the Maui hybridization system. Slides were washed for 4 minutes in both buffers 1 (1× SSC (Life Technologies) with 0.1\% SDS (Sigma-Aldrich, St. Louis, MO)) and $2(0.1 \times$ SSC), and then dried for 2 minutes during centrifugation. Samples from each donor at each passage were run in triplicate in a randomized block design to reduce possible nuisance factors (Figure 1A).

\section{Data acquisition and analysis}

Microarray images were collected by using the 4000B GenePix Axon Scanner (Axon Instruments Inc., Union City, CA). Slides were scanned at $532 \mathrm{~nm}$ for $\mathrm{Cy} 3$ and $635 \mathrm{~nm}$ for Hyper5 with an image resolution of $5 \mu \mathrm{m}$. Spots were annotated by aligning them to the gene-array list (Gal file) that was generated according to the printing orientation, and the data were acquired by GenePix Pro. ArrayTrack software was used to normalized data by using linear and Lowess methods by using the
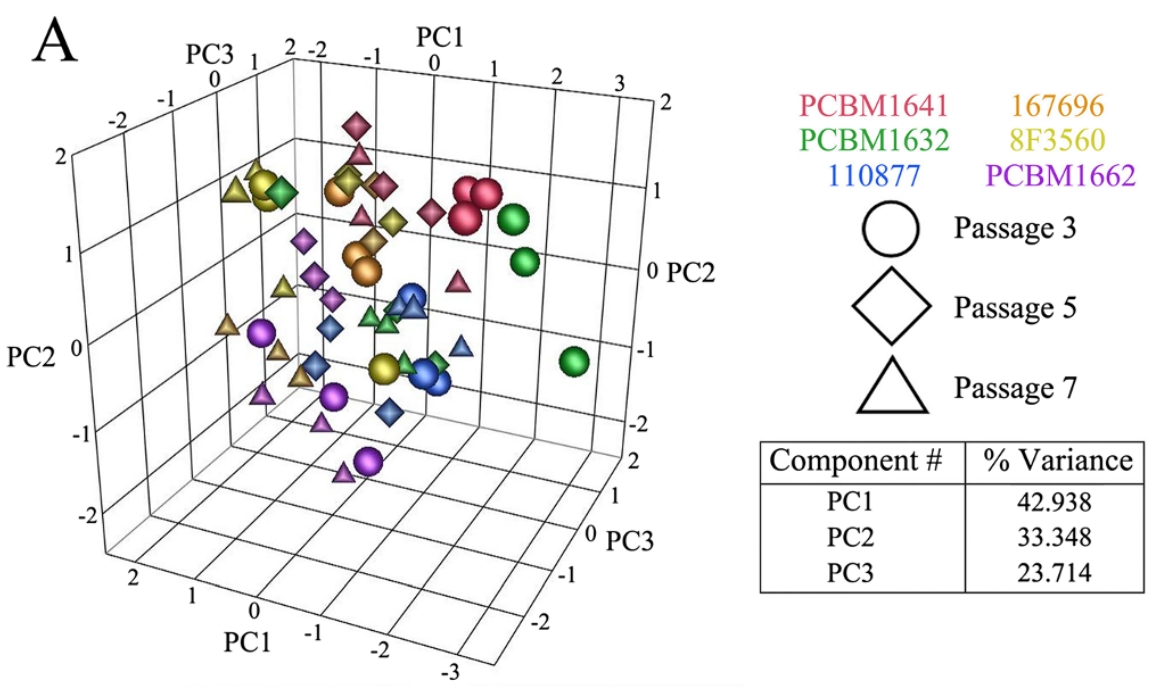

\begin{tabular}{|c|c|}
\hline Component \# & \% Variance \\
\hline PC1 & 42.938 \\
PC2 & 33.348 \\
PC3 & 23.714 \\
\hline
\end{tabular}
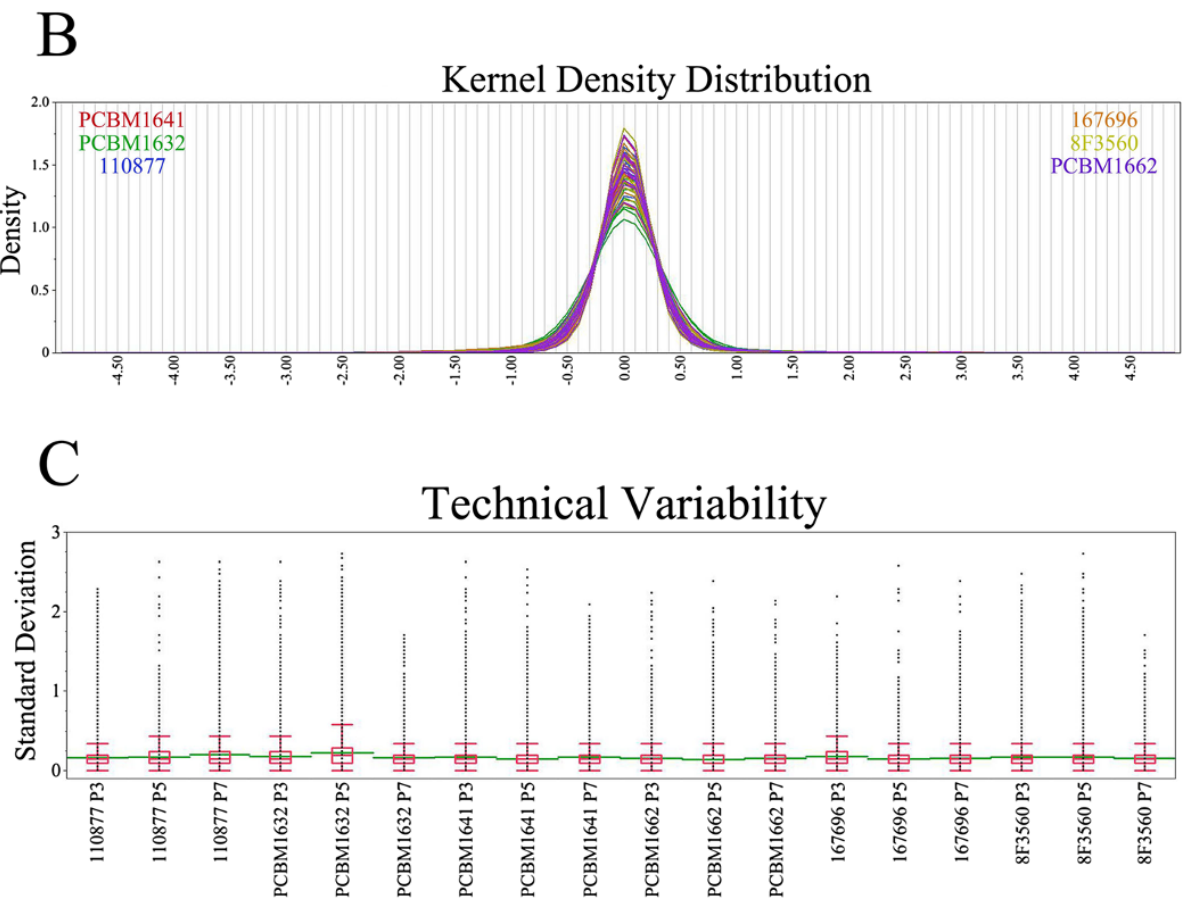

Figure 1 Global microarray analysis of gene expression. (A) Unsupervised three-dimensional representations of principal components 1, 2, and 3 for each microarray for the six donors cultured to passage 7, run in triplicate, for a total of 54 microarrays. Each symbol (circle, diamond, triangle) represents one sample on one microarray containing 35,035 probes. (B) Kernel density plots of normalized data for each of the donor/ passage replicates. (C) Box-plot distributions of the technical variability per probe for each donor/passage. 
median intensities [42]. JMP Genomics 3 software was used to perform all calculations and statistical analyses, including principal component analysis, hierarchic clustering, box plots, and the repeated measures analysis of variance (ANOVA) models. Microarray data files have been uploaded into the public repository Gene Expression Omnibus (GSE56362).

All 34,555 probes, excluding controls, were initially filtered by the technical and biologic variability and the magnitude of their expression level, as determined by the A signal $\left(\log _{2}(\mathrm{Cy} 3 \times \text { Hyper } 5)^{1 / 2}\right)$. In the technicalvariability filtering step, the standard deviation of the gene-expression ratio, $\log _{2}$ (Hyper5/Cy3), was calculated between technical replicates of identical donors/passages for each probe. The median technical variability per probe was calculated by taking the median of the 18 (six donors at three passages each) individual standard deviations.

Probes whose difference between passages 3 and 7 was less than the technical-variability cutoff were eliminated. To filter probes by their biologic variability, a paired $t$ test was used between expression values at passage 3 and 7.

Probes were removed from the dataset if their $P$ value was greater than or equal to 0.05 . For the magnitude of expression filtering step, a background cutoff was calculated from the mean and standard deviation of the A signals from 2,489 negative controls and empty wells for all the microarrays.

Probes whose mean A signals at passage 3 and 7 were both less than the background cutoff (mean A signal plus 1 standard deviation) were eliminated [43]. After filtering, a repeated-measures ANOVA model using compound symmetry correlation structure and pairwise comparisons between passages was performed for each probe (911 probes total) by using $t$ statistics after accounting for the chosen variance-covariance structure. The Cy3 expression value signal was added to each repeatedmeasure ANOVA model as a covariate to account for variability in the experimental units for each probe.

Multiplicity adjustment by using a $P$ value threshold of $<0.001$ (with a corresponding false discovery rate of 0.023 [44]) was also applied for all pairwise comparisons between passages (911 probes $\times$ three pairwise comparisons $=2,733 P$ values). A Fisher Exact test was used by Ingenuity Pathway Analysis (IPA) software to calculate the range of $P$ values for the each biofunction.

\section{Cell-proliferation assay}

The Click-iT EdU cell-proliferation assay (Life Technologies) was used to evaluate cell division per the manufacturer's instructions. In brief, MSCs from four different donors at passages 3 and 7 were plated on a 24-multiwell dish at a density of 5,000 cells $/ \mathrm{cm}^{2}$. Once adhered, cells were mixed with the EdU reagent for both 6 and 18 hours.
After the specified time in culture, MSCs were fixed and stained with Alexa Fluor 488 for EdU detection. The cell nuclei were visualized with Hoechst 33342 (Life Technologies) at a concentration of $5 \mu \mathrm{g} / \mathrm{ml}$. Automated microscopy with a Nikon Ti-S inverted microscope with a $10 \times$ objective was performed to acquire fluorescence images at 15 randomized locations per well. All MSC donors, passages, and time points were repeated in quadruplicate, and CellProfiler version 2.0 was used to determine the percentage of EdU-positive cells. A paired $t$ test was used to determine statistical differences in EdU expression of MSCs between passages 3 and 7 at both 6 and 18 hours in culture.

\section{Results}

Global microarray analysis of gene expression in MSCs

For gene-expression analysis, a randomized block design for the two-color gene expression microarrays with a reference was used to eliminate bias from microarrays performed at different times (Additional file 1: Figure S1). Linear and Lowess normalization rendered nearly identical normally distributed gene-expression signals $\left(\log _{2}\right.$ (Sample/Reference)) for all the arrays with a mean centered near zero (Figure 1B). This aided in eliminating bias that may result at subsequent steps during the analysis by ensuring that differences were due to passage and not differences in signal range. An unsupervised principalcomponent analysis of the six cell lines expanded to passage 7 was performed, and the percentage variance for the first three principal components 1, 2, and 3, are 42.938, 33.348, and 23.714, respectively (Figure 1A). No single principal component captured a majority of the variance, indicating that no clear distinction exists between MSCs from different donors or passages. Instead, some minor clustering occurs among technical replicates. Furthermore, the technical variability per probe was very low, with a mean range of 0.1483 to 0.2257 for all donors/passages (Figure $1 \mathrm{C}$, green line).

\section{Gene filtering}

The objective of this study was to identify gene markers indicating MSC aging in culture across all donors. This provided the basis for the filtering process in which probes exhibiting differences between passage 3 and 7 were more useful in terms of identification markers than were differences observed between passages 3 and 5 or passages 5 and 7. To identify probes with consistent upor downregulation with passage and therefore to minimize the number of candidates, three robust filtering steps were used: technical and biologic variability and their magnitude of expression (Additional file 1: Figure S1). The calculated difference in gene expression between passages 3 and 7 for a single probe may be indistinguishable, based on the limitations of the microarray 
technology; therefore it is essential to reduce type I errors by determining a technical-variability cutoff per probe. A technical-variability cutoff was calculated by using standard deviations of the technical replicates from 18 different samples.

Probes whose absolute mean difference between passages 3 and 7, not greater than this cutoff, were eliminated from the dataset, resulting in 6,219 probes (Figure 2A).

Other investigators commonly choose an arbitrary foldchange cutoff of 2 as a method to distinguish two conditions as technical replication with microarrays, because microarrays are costly $[45,46]$. Although this is generally a good rule of thumb, it often necessitates verification by real-time quantitative PCR to ensure the technical variability of the system using microarrays is not greater than twofold itself.
The other problem is that genes exhibiting a less than twofold change may be of biologic value, but they are often overlooked because of choosing an arbitrary cutoff. Because each sample in these experiments was repeated in triplicate, the technical variability can be calculated to eliminate genes with low fold changes, but still have detectable differences between two conditions (that is, passage 3 and 7 cells).

Biologic variability between MSCs from different donors can have a major impact on the identification of marker genes. Likewise, it is beneficial to eliminate genes whose differences between passages 3 and 7 are highly variable between donors, because the goal is to find probes that can be used as reproducible gene markers. These remaining probes were then filtered by their biologic variability by means of a paired $t$ test $(\alpha=0.05)$ between passages 3 and 7 . This eliminated probes in which
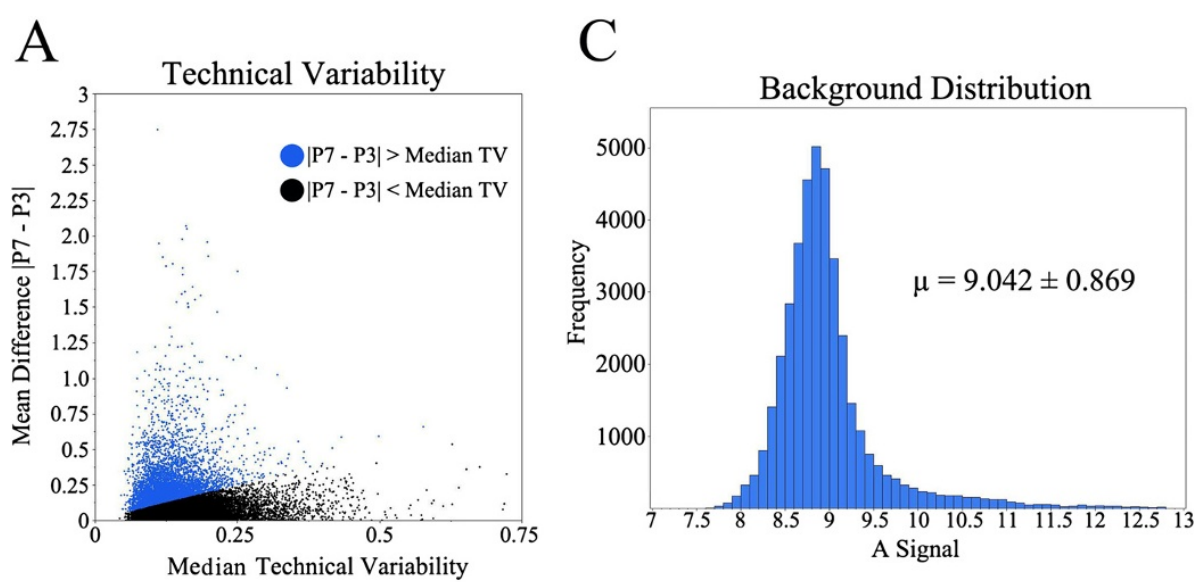

B

$\mathrm{D}$
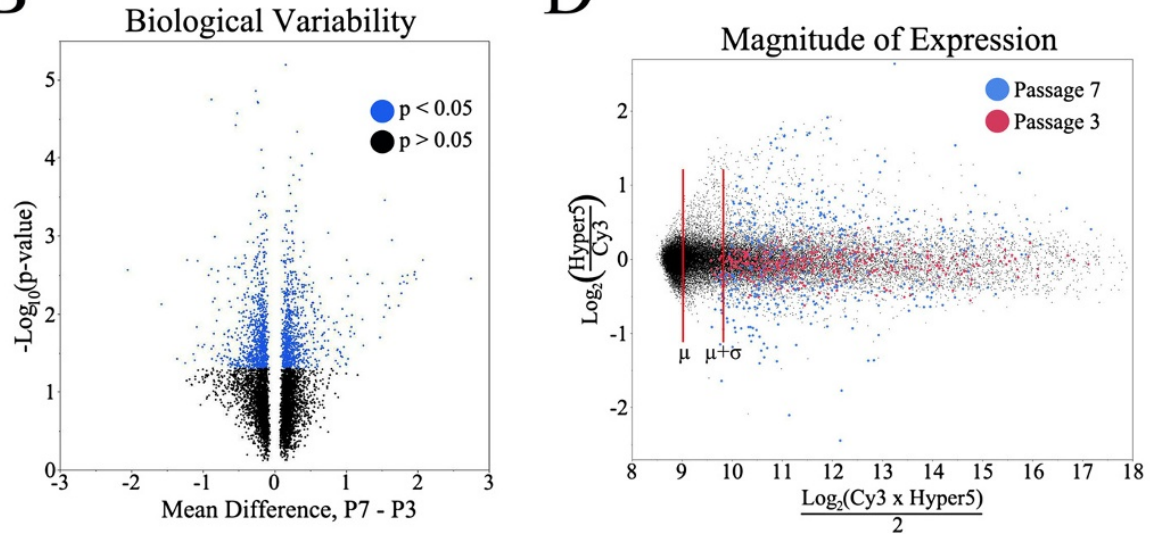

Figure 2 Gene filtration. (A) The mean difference between passage 7 and passage 3 versus the technical-variability cutoff point per probe for 34,555 probes. Blue probes $(6,219)$ indicate that the differences between passages 7 and 3 are measurable. Blue probes were above the cutoff and used in further analysis, and black probes were below the cutoff and not used in further analysis. (B) Volcano plot of the mean difference between passages 7 and 3 versus - Log 10 ( $P$ value). Blue probes $(1,713)$ indicate that the differences between passages 7 and 3 are greater than the biologic variability. (C) Distribution of the A signals of the background spots with a mean and standard deviation of 9.042 \pm 0.869 . (D) MA plot of all the probes on the microarray. The blue spots represent the mean gene expression and A signal of the 911 probes at passage 7, and the red spots represent the mean gene expression and A signal at passage 3. The mean of the background $(\mu)$ and the mean of the background plus 1 standard deviation $(\mu+\sigma)$ are indicated by the red vertical lines. 
the differences in gene expression between passages 3 and 7 of individual donors were highly variable, thus resulting in 1,713 probes (Figure $2 \mathrm{~B}$ ).

To filter probes based on the magnitude of their expression, the background A signal was calculated for empty wells and negative controls, where the signal should be zero. The background signal was normally distributed, with a mean and standard deviation of $9.042 \pm 0.869$ (Figure 2C). Probes whose mean A signal was not greater than the background cutoff at passage 3 or 7 were eliminated from the dataset. If the mean A signal was greater than the background cutoff for only one of the passages, then the probe was considered expressed. The mean gene expression and A signal for 911 probes that passed each filtering step are visualized on an MA (log of the ratio versus log of the mean) plot for passages 3 and 7 (Figure 2D).

\section{Identification of gene markers as a result of cell culture} The MSCs expressed the ISCT markers CD29+, CD44+, CD73+, CD90+, CD105+, and CD166+ consistently through cell passaging, with no statistically significant differences observed [47]. With a repeated-measures ANOVA with pairwise comparisons between passages and multiplicity adjustment, the data resulted in 99 statistically significant probes. In total, the 99 probes amounted to 81 genes that were significantly different between passages 3 and 7 , where three genes are of an unknown classification (Table 2). Significant changes were not observed for any of the ISCT criteria markers; CD105+ (ENG), CD73+ (NT5E), CD90+ (THY1), CD45- (PTPRC), CD34-, CD14-, CD11b(ITGAM), CD79 $\alpha-(I G A)$, CD19- (B4), and HLA-DR, nor other known classification markers, CD29+ (ITGB1), CD166+ (ALCAM), and CD133- (PROM1). Four genes, KRT18 (16), ITGBL1 (2), NTN4 (2), and RBPMS (2), were spotted multiple times as different sequences across the microarray and determined to be statistically significant. Of the 78 known genes that were found to be significantly different, only one of the genes was not found to be significant between passages 3 and 7, whereas only eight genes were significantly different between passages 3 and 5 , and three genes were significantly different between passages 5 and 7 (Figure 3B). No genes were found to be statistically significant between all combinations of passages.

In comparing gene expression between both vendors Lonza and ALLCELLS at passage 3, no statistically significant differences were found.

Hierarchic clustering by genes and passage revealed the relative changes in expression from passages 3 to 7 of the 78 different known genes (Figure 3A). The expression profile of genes at passage 5 clustered more closely with passage 7 . Three clusters of genes exhibited upregulation from passages 3 to 7, whereas another three clusters exhibited downregulation from passages 3 to 7 .
The top upregulated genes at passage 7 compared with passage 3 were KRT18, NTN4, and BST1, with fold changes of 3.62, 2.68, and 2.46, respectively (Table 2). The top downregulated genes were PENK, COL12A1, and $B A A L C$, with fold changes of $-4.15,-3.00$, and -2.33 , respectively. The smallest fold changes detected for statistically significant genes were ATP5E, upregulated at 1.10, and $A G K$, downregulated at -1.10 . A supervised principal-component analysis of the 78 statistically significant genes (represented by the 99 probes) between passages 3 and 7 reveals a clear separation between both passages, with a majority of the percentage variance captured in the first principal component with $60.619 \%$, followed by $33.426 \%$ for principal component 2 and $5.955 \%$ for principal component 3 (Figure 3C). Principal components 1 and 2 for the passage 3 donor samples cluster closely with technical replicates; however, the distinct separation indicates the biologic variability between donors resulting from the identified genes. By passage 5, samples represented by both the first two principal components are intermixed with each other and samples at passage 7; thus MSCs exhibit a greater similarity with passaging.

IPA software was accessed on August 27, 2013, and the 78 significant genes were uploaded to their database, of which 74 genes were mapped. These were found to be distributed throughout all compartments of the cell, with $34.6 \%$ in the cytoplasm, $6.4 \%$ in the extracellular space, $21.8 \%$ in the nucleus, $16.7 \%$ in the plasma membrane, and $20.5 \%$ in an unknown location (Table 2). The top molecular and cellular functions and physiological system development and functions were predicted by the IPA software (Table 3). A majority of the significant genes were observed to have involvement in the categories of cellular development, cellular growth and proliferation, and tissue development.

\section{Comparison of gene-expression changes and cellular proliferation}

Because a majority of genes that were modulated as a result of cellular passage belonged to cellular growth and proliferation, we performed cell-proliferation assays on MSCs in passages 3 and 7. An EdU cell-proliferation assay was used to evaluate differences in cell proliferation between passages 3 and 7 (Figure 4A). Despite the variability in cell proliferation and percentage of cells dividing between donors at a given passage, MSCs exhibited a significantly greater potential for cell division at passage 3, as more cells incorporated EdU in comparison to passage 7 , at both time points (Figure $4 B, C$ ). The fold changes in cellular proliferation between passages 3 and 7 were -1.62 and -1.42 when measured at 6 and 18 hours, respectively. 
Table $2 \mathrm{~A}$ list of statistically significant $(P<0.001)$ genes with indicated fold changes $\left(\log _{2}(\right.$ fold change))

\begin{tabular}{|c|c|c|c|c|c|c|c|c|c|}
\hline \multirow[t]{2}{*}{ Number } & \multirow{2}{*}{$\begin{array}{l}\text { Gene accession } \\
\text { number }\end{array}$} & \multirow[t]{2}{*}{ Gene name } & \multirow{2}{*}{$\begin{array}{l}\text { Gene } \\
\text { symbol }\end{array}$} & \multirow[t]{2}{*}{ Location } & \multicolumn{3}{|c|}{ Mean fold change (MFC) } & \multirow{2}{*}{$\begin{array}{l}\text { Technical } \\
\text { variability }\end{array}$} & \multirow{2}{*}{$\begin{array}{l}\text { Biologic } \\
\text { variability } \\
\text { (P7/P3) } \\
\text { (P5/P3) } \\
\text { (P7/P5) }\end{array}$} \\
\hline & & & & & P7/P3 ( $\left.\log _{2}(\mathrm{MFC})\right)$ & P5/P3 ( $\left.\log _{2}(M F C)\right)$ & P7/P5 ( $\left.\log _{2}(M F C)\right)$ & & \\
\hline \multirow[t]{2}{*}{1} & NM_003816 & ADAM metallopeptidase domain 9 & ADAM9 & Plasma membrane & $1.25(0.321)$ & NS & NS & 0.112 & 0.226 \\
\hline & & & & & & & & & $\begin{array}{l}- \\
-\end{array}$ \\
\hline \multirow[t]{2}{*}{2} & XM_005248381 & $\begin{array}{l}\text { ADAM } 7 \text { metallopeptidase with } \\
\text { thrombospondin type } 1 \text { motif, } 12\end{array}$ & ADAMTS12 & Unknown & $1.59(0.672)$ & NS & NS & 0.143 & $\begin{array}{c}0.477 \\
-\end{array}$ \\
\hline & & & & & & & & & - \\
\hline \multirow[t]{3}{*}{3} & NM_018238 & Acylglycerol kinase & AGK & Cytoplasm & $-1.10(-0.133)$ & NS & $-1.13(-0.170)$ & 0.128 & 0.110 \\
\hline & & & & & & & & & - \\
\hline & & & & & & & & & 0.163 \\
\hline \multirow[t]{2}{*}{4} & NM_001199183 & $\begin{array}{l}\text { ATPase, } \mathrm{Ca}^{2} \text { transporting, type } 2 \mathrm{C} \text {, } \\
\text { member } 1\end{array}$ & ATP2C1 & Cytoplasm & $1.47(0.555)$ & NS & NS & 0.101 & 0.325 \\
\hline & & & & & & & & & - \\
\hline \multirow[t]{3}{*}{5} & NM_006886 & ATP synthase, $\mathrm{H}+$ transporting, & ATP5E & Cytoplasm & $1.10(0.142)$ & $1.10([0.133)$ & NS & 0.092 & 0.069 \\
\hline & & subunit & & & & & & & 0.084 \\
\hline & & & & & & & & & \\
\hline \multirow[t]{3}{*}{6} & NM_000489 & Alpha thalassemia/mental retardation & ATRX & Nucleus & $1.18(0.242)$ & NS & NS & 0.108 & 0.191 \\
\hline & & syndrome $x$-IInked & & & & & & & - \\
\hline & & & & & & & & & - \\
\hline \multirow[t]{3}{*}{7} & NM_024812 & Brain and acute leukemia, cytoplasmic & BAALC & Cytoplasm & $-2.33(-1.223)$ & NS & NS & 0.105 & 0.509 \\
\hline & & & & & & & & & - \\
\hline & & & & & & & & & - \\
\hline \multirow[t]{3}{*}{8} & NM_015379 & Brain protein 13 & BRI3 & Unknown & $1.26(0.333)$ & NS & NS & 0.112 & 0.237 \\
\hline & & & & & & & & & - \\
\hline & & & & & & & & & - \\
\hline \multirow[t]{3}{*}{9} & NM_004334 & Bone marrow stromal cell antigen 1 & BST1 & Plasma membrane & $2.46(1.297)$ & NS & NS & 0.134 & 0.595 \\
\hline & & & & & & & & & - \\
\hline & & & & & & & & & - \\
\hline 10 & NM_001206748 & Caveolin 2 & CAV2 & Plasma membrane & $1.35(0.438)$ & NS & NS & 0.207 & 0.309 \\
\hline
\end{tabular}


Table 2 A list of statistically significant $\left(P<\mathbf{0 . 0 0 1 )}\right.$ genes with indicated fold changes $\left(\log _{\mathbf{2}}(\right.$ fold change)) $($ Continued)

\begin{tabular}{|c|c|c|c|c|c|c|c|c|c|}
\hline 11 & NM_174908 & Coiled-coil domain containing 50 & CCDC50 & Cytoplasm & $1.25(0.322)$ & NS & NS & 0.113 & $\begin{array}{c}0.194 \\
- \\
-\end{array}$ \\
\hline 12 & NM_003903 & $\begin{array}{l}\text { Cell division cycle } 16 \text { homolog } \\
\text { (Saccharomyces cerevisiae) }\end{array}$ & CDC16 & Nucleus & $1.16(0.218)$ & NS & NS & 0.093 & 0.059 \\
\hline 13 & NM_006319 & $\begin{array}{l}\text { CDP-diacylglycerol-inositol 3- } \\
\text { phosphatidyltransferase }\end{array}$ & CDIPT & Cytoplasm & $1.27(0.345)$ & NS & NS & 0.173 & 0.270 \\
\hline 14 & NM_001799 & Cyclin-dependent kinase 7 & CDK7 & Nucleus & $1.21(0.278)$ & NS & NS & 0.107 & 0.143 \\
\hline & & & & & & & & & - \\
\hline 15 & NM_001195132 & $\begin{array}{l}\text { Cyclin-dependent kinase inhibitor 2A } \\
\text { (melanoma, p16, inhibits CDK4) }\end{array}$ & CDKN2A & Nucleus & $1.37(0.452)$ & NS & NS & 0.104 & 0.402 \\
\hline & & & & & & & & & - \\
\hline 16 & NM_001854 & Collagen, type XI, alpha 1 & COL11A1 & Extracellular space & $-2.19(-1.132)$ & NS & NS & 0.243 & $\begin{array}{c}0.947 \\
- \\
-\end{array}$ \\
\hline 17 & NM_004370 & Collagen, type XII, alpha 1 & COL12A1 & Extracellular space & $-3.00(-1.583)$ & NS & NS & 0.185 & $\begin{array}{c}0.895 \\
- \\
-\end{array}$ \\
\hline 18 & NM_032609 & $\begin{array}{l}\text { Cytochrome c oxidase subunit IV } \\
\text { isoform } 2 \text { (lung) }\end{array}$ & $\operatorname{cox} 412$ & Cytoplasm & $-1.33(-0.407)$ & NS & NS & 0.140 & $\begin{array}{c}0.183 \\
- \\
-\end{array}$ \\
\hline 19 & NM_000100 & Cystatin B (stefin B) & CSTB & Cytoplasm & $1.25(0.323)$ & NS & NS & 0.078 & $\begin{array}{c}0.262 \\
- \\
-\end{array}$ \\
\hline 20 & NG_021375 & Discs, large homolog 2 (Drosophila) & DLG2 & Unknown & $1.43(0.521)$ & NS & NS & 0.106 & $\begin{array}{c}0.263 \\
- \\
-\end{array}$ \\
\hline 21 & NM_025219 & $\begin{array}{l}\text { DNAJ (Hsp40) homolog, subfamily C, } \\
\text { member } 5\end{array}$ & DNAJC5 & Plasma membrane & $1.27(0.342)$ & NS & NS & 0.134 & 0.289 \\
\hline
\end{tabular}


Table 2 A list of statistically significant $(P<0.001)$ genes with indicated fold changes $\left(\log _{\mathbf{2}}(\right.$ fold change)) $($ Continued)

\begin{tabular}{|c|c|c|c|c|c|c|c|c|c|}
\hline 22 & NM_005740 & Dynein, axonemal, light chain 4 & DNAL4 & Cytoplasm & $1.54(0.626)$ & NS & NS & 0.138 & $\begin{array}{c}0.335 \\
- \\
-\end{array}$ \\
\hline 23 & NM_001009933 & Deoxyribonuclease I-like 1 & DNASE1L1 & Cytoplasm & $1.47(0.559)$ & NS & NS & 0.102 & $\begin{array}{c}0.336 \\
- \\
-\end{array}$ \\
\hline 24 & NM_033407 & Dedicator of cytokinesis 7 & DOCK7 & Plasma membrane & $1.29(0.370)$ & NS & NS & 0.116 & $\begin{array}{c}0.249 \\
- \\
-\end{array}$ \\
\hline 25 & NM_020390 & $\begin{array}{l}\text { Eukaryotic translation initiation factor } \\
5 \mathrm{~A} 2\end{array}$ & EIF5A2 & Cytoplasm & $1.17(0.227)$ & NS & NS & 0.142 & $\begin{array}{c}0.115 \\
- \\
-\end{array}$ \\
\hline 26 & NM_014568 & $\begin{array}{l}\text { UDP-N-acetyl-alpha-D-galactosamine: } \\
\text { polypeptide } N \text { - } \\
\text { acetylgalactosaminyltransferase } 5 \\
\text { (GalNAc-T5) }\end{array}$ & GALNT5 & Cytoplasm & $2.01(1.005)$ & $1.63(0.705)$ & NS & 0.074 & $\begin{array}{c}0.620 \\
0.216 \\
-\end{array}$ \\
\hline 27 & NM_001523 & Hyaluronan synthase 1 & HAS1 & Plasma membrane & $-1.84(-0.882)$ & $-1.42(-0.507)$ & NS & 0.112 & $\begin{array}{c}0.136 \\
0.132 \\
-\end{array}$ \\
\hline 28 & XM_005249437 & Histone cluster 1, H2ac & HIST1H2AC & Unknown & $1.99(0.992)$ & NS & NS & 0.159 & $\begin{array}{c}0.904 \\
- \\
-\end{array}$ \\
\hline 29 & NM_003535 & Histone cluster 1, H3j & HIST1H3J & Nucleus & $-1.22(-0.286)$ & NS & NS & 0.136 & $\begin{array}{c}0.200 \\
- \\
-\end{array}$ \\
\hline 30 & NM_001130688 & High-mobility group box 2 & HMGB2 & Nucleus & $-1.18(-0.239)$ & NS & NS & 0.082 & $\begin{array}{c}0.135 \\
- \\
-\end{array}$ \\
\hline 31 & XM_005266269 & $\begin{array}{l}\text { Heterogeneous nuclear } \\
\text { ribonucleoprotein A1-like } 2\end{array}$ & HNRNPA1L2 & Unknown & $-1.47(-0.557)$ & NS & NS & 0.084 & $\begin{array}{c}0.489 \\
- \\
-\end{array}$ \\
\hline 32 & NM_004791 & $\begin{array}{l}\text { Integrin, beta-like } 1 \text { (with EGF-like repeat } \\
\text { domains) }\end{array}$ & ITGBL1 ${ }^{\mathrm{a}}(2)$ & Unknown & $1.56(0.639)$ & NS & NS & 0.120 & 0.504 \\
\hline
\end{tabular}


Table 2 A list of statistically significant $\left(P<\mathbf{0 . 0 0 1 )}\right.$ genes with indicated fold changes $\left(\log _{\mathbf{2}}(\right.$ fold change)) $($ Continued)

\begin{tabular}{|c|c|c|c|c|c|c|c|c|c|}
\hline 33 & NM_015167 & Jumonji domain containing 6 & JMJD6 & Plasma membrane & $-1.16(-0.220)$ & NS & NS & 0.100 & $\begin{array}{c}0.108 \\
- \\
-\end{array}$ \\
\hline 34 & NG_028043 & Kinesin family member $16 \mathrm{~B}$ & KIF16B & Cytoplasm & $2.04(1.027)$ & $1.62(0.697)$ & NS & 0.094 & $\begin{array}{c}0.547 \\
0.175 \\
-\end{array}$ \\
\hline 35 & NM_001300 & Kruppel-like factor 6 & KLF6 & Nucleus & $-1.43(-0.518)$ & NS & NS & 0.148 & $\begin{array}{c}0.086 \\
-\end{array}$ \\
\hline 36 & NM_000223 & Keratin 12 & KRT12 & Cytoplasm & $1.51(0.598)$ & NS & NS & 0.234 & $\begin{array}{c}0.377 \\
-\end{array}$ \\
\hline 37 & NM_199187 & Keratin 18 & KRT18 ${ }^{\mathrm{a}}(16)$ & Cytoplasm & $3.62(1.813)$ & $2.34(1.205)$ & NS & 0.157 & $\begin{array}{c}0.891 \\
0.497 \\
-\end{array}$ \\
\hline 38 & NM_001080978 & $\begin{array}{l}\text { Leukocyte immunoglobulin-like } \\
\text { receptor, subfamily B (with TM and ITIM } \\
\text { domains), member } 2\end{array}$ & LILRB2 & Plasma membrane & $1.11(0.156)$ & NS & NS & 0.151 & $\begin{array}{c}0.147 \\
- \\
-\end{array}$ \\
\hline 39 & NM_144703 & $\begin{array}{l}\text { LSM14B, SCD6 homolog B } \\
\text { (Saccharomyces cerevisiae) }\end{array}$ & LSM14B & Unknown & $-1.12(-0.165)$ & NS & NS & 0.116 & $\begin{array}{c}0.118 \\
- \\
-\end{array}$ \\
\hline 40 & NM_020152 & MAP3K7 C-terminal like & MAP3K7CL & Unknown & $2.36(1.238)$ & NS & NS & 0.13 & $\begin{array}{c}0.962 \\
- \\
-\end{array}$ \\
\hline 41 & NG_013325 & Mitogen-activated protein kinase 10 & MAPK10 & Cytoplasm & $-1.15(-0.201)$ & $-1.15(-0.199)$ & NS & 0.146 & $\begin{array}{c}0.172 \\
0.196 \\
-\end{array}$ \\
\hline 42 & NM_138799 & $\begin{array}{l}\text { Membrane bound O-acyltransferase } \\
\text { domain containing } 2\end{array}$ & MBOAT2 & Cytoplasm & $-1.26(-0.338)$ & NS & NS & 0.105 & $\begin{array}{c}0.279 \\
- \\
-\end{array}$ \\
\hline 43 & NR_002766 & $\begin{array}{l}\text { Maternally expressed } 3 \text { (nonprotein } \\
\text { coding) }\end{array}$ & MEG3 & Unknown & $1.41(0.505)$ & NS & NS & 0.218 & 0.359 \\
\hline
\end{tabular}


Table $2 \mathrm{~A}$ list of statistically significant $\left(\boldsymbol{P}<\mathbf{0 . 0 0 1 )}\right.$ genes with indicated fold changes $\left(\log _{\mathbf{2}}(\right.$ fold change $\left.)\right)($ Continued)

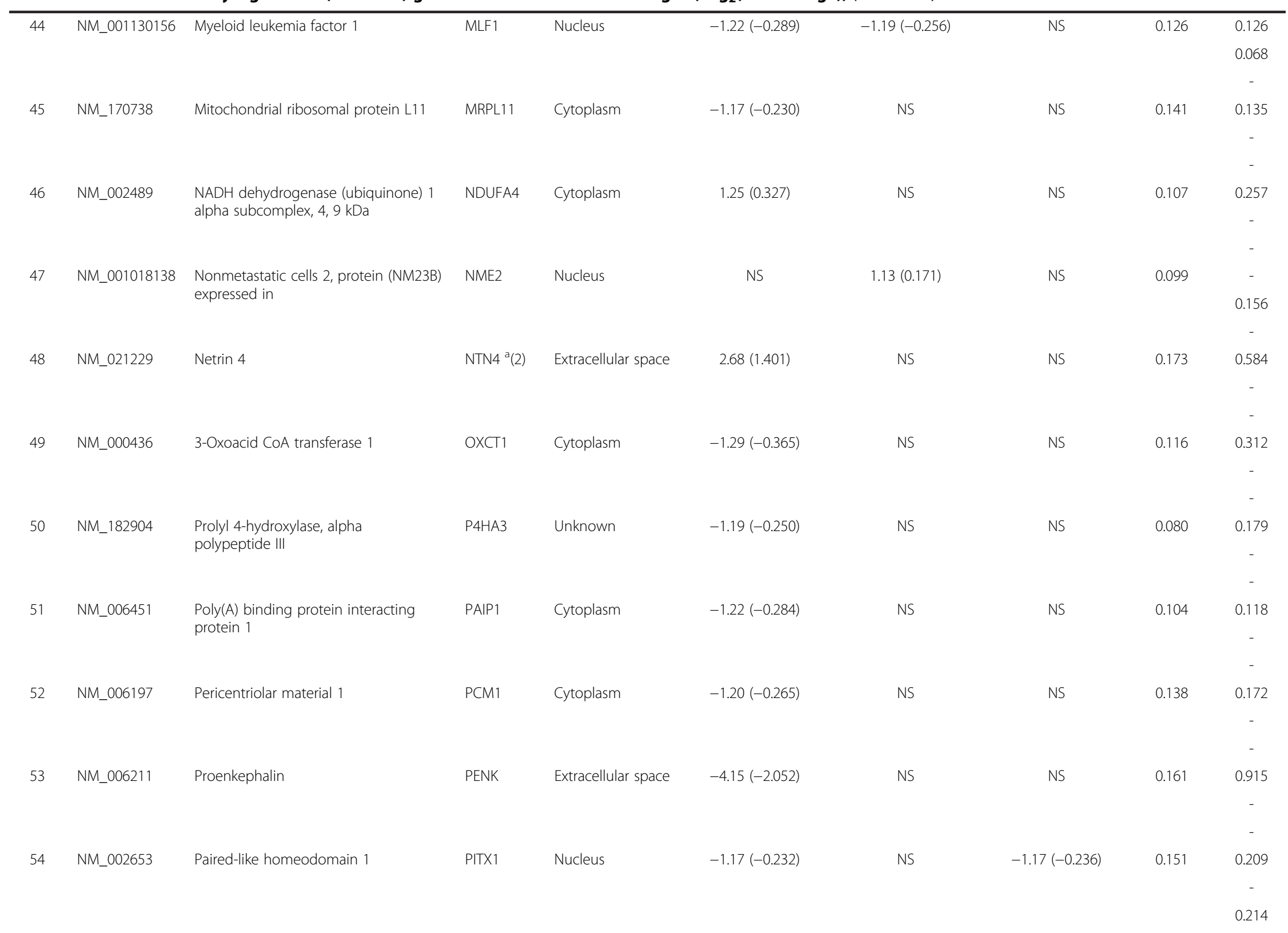


Table 2 A list of statistically significant $(P<0.001)$ genes with indicated fold changes $\left(\log _{\mathbf{2}}(\right.$ fold change)) $($ Continued)

\begin{tabular}{|c|c|c|c|c|c|c|c|c|c|}
\hline 55 & NM_001172335 & Plastin 3 & PLS3 & Cytoplasm & $1.43(0.515)$ & NS & NS & 0.136 & $\begin{array}{c}0.298 \\
- \\
-\end{array}$ \\
\hline 56 & NM_006406 & Peroxiredoxin 4 & PRDX4 & Cytoplasm & $1.23(0.301)$ & NS & NS & 0.102 & $\begin{array}{c}0.206 \\
- \\
-\end{array}$ \\
\hline 57 & NM_182663 & $\begin{array}{l}\text { Ras association (RalGDS/AF-6) domain } \\
\text { family member } 5\end{array}$ & RASSF5 & Plasma membrane & $1.93(0.947)$ & NS & NS & 0.118 & $\begin{array}{c}0.553 \\
- \\
-\end{array}$ \\
\hline 58 & NM_006867 & $\begin{array}{l}\text { RNA-binding protein with multiple } \\
\text { splicing }\end{array}$ & RBPMS ${ }^{a}(2)$ & Unknown & $1.23(0.298)$ & NS & NS & 0.111 & $\begin{array}{c}0.111 \\
- \\
-\end{array}$ \\
\hline 59 & NM_006802 & Splicing factor 3a, subunit 3, $60 \mathrm{kDa}$ & $\mathrm{SF} 3 \mathrm{~A} 3$ & Nucleus & $-1.26(-0.333)$ & NS & NS & 0.130 & $\begin{array}{c}0.284 \\
- \\
-\end{array}$ \\
\hline 60 & NM_003028 & $\begin{array}{l}\text { Src homology } 2 \text { domain containing } \\
\text { adaptor protein B }\end{array}$ & SHB & Cytoplasm & $1.33(0.407)$ & NS & NS & 0.118 & $\begin{array}{c}0.203 \\
- \\
-\end{array}$ \\
\hline 61 & NM_001142392 & $\begin{array}{l}\text { Solute carrier family } 10 \text { (sodium/bile } \\
\text { acid cotransporter family), member } 3\end{array}$ & SLC10A3 & Plasma membrane & $1.20(0.261)$ & NS & NS & 0.184 & $\begin{array}{c}0.156 \\
- \\
-\end{array}$ \\
\hline 62 & NM_005072 & $\begin{array}{l}\text { Solute carrier family } 12 \text { (potassium/ } \\
\text { chloride transporters), member } 4\end{array}$ & SLC12A4 & Plasma membrane & $1.34(0.424)$ & NS & NS & 0.118 & $\begin{array}{c}0.278 \\
- \\
-\end{array}$ \\
\hline 63 & NM_005073 & $\begin{array}{l}\text { Solute carrier family } 15 \text { (oligopeptide } \\
\text { transporter), member } 1\end{array}$ & SLC15A1 & Plasma membrane & $1.17(0.228)$ & NS & NS & 0.201 & $\begin{array}{c}0.109 \\
- \\
-\end{array}$ \\
\hline 64 & NM_001166695 & $\begin{array}{l}\text { Solute carrier family } 1 \text { (glial high-affinity } \\
\text { glutamate transporter), member } 3\end{array}$ & SLC1A3 & Plasma membrane & $-1.72(-0.786)$ & NS & NS & 0.183 & $\begin{array}{c}0.352 \\
- \\
-\end{array}$ \\
\hline 65 & NM_032315 & Solute carrier family 25, member 33 & SLC25A33 & Cytoplasm & $-1.12(-0.164)$ & NS & NS & 0.144 & 0.139 \\
\hline
\end{tabular}


Table 2 A list of statistically significant $(P<0.001)$ genes with indicated fold changes $\left(\log _{\mathbf{2}}(\right.$ fold change)) $($ Continued)

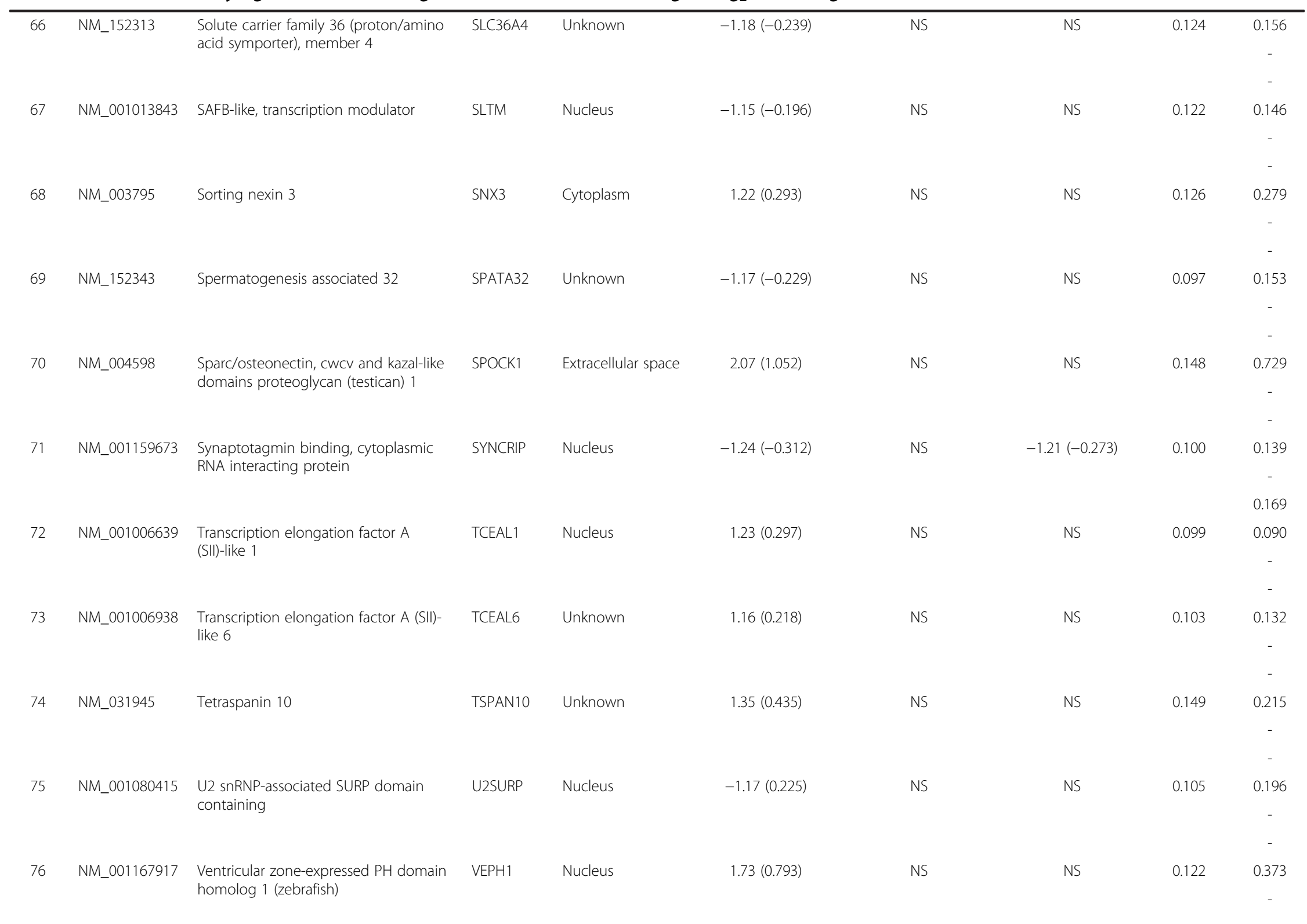


Table $2 \mathrm{~A}$ list of statistically significant $(P<0.001)$ genes with indicated fold changes $\left(\right.$ Log $_{2}$ (fold change)) (Continued)

\begin{tabular}{|c|c|c|c|c|c|c|c|c|c|}
\hline 77 & NM_006297 & $\begin{array}{l}\text { X-ray repair complementing defective } \\
\text { repair in Chinese hamster cells } 1\end{array}$ & $\mathrm{XRCC1}$ & Nucleus & $-1.14(-0.190)$ & NS & NS & 0.139 & 0.101 \\
\hline & & & & & & & & & - \\
\hline 78 & NM_015144 & Zinc finger, $\mathrm{CCHC}$ domain containing 14 & $\mathrm{ZCCHC14}$ & Unknown & $-1.18(-0.235)$ & NS & NS & 0.152 & 0.156 \\
\hline
\end{tabular}

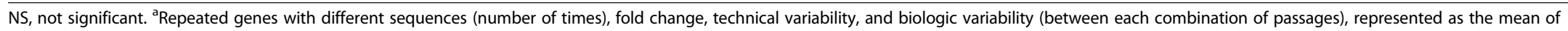
repeated genes sequences. For "-" listed in the biologic-variability column, the value is not provided for a given passage if significance was not found between two passages. 


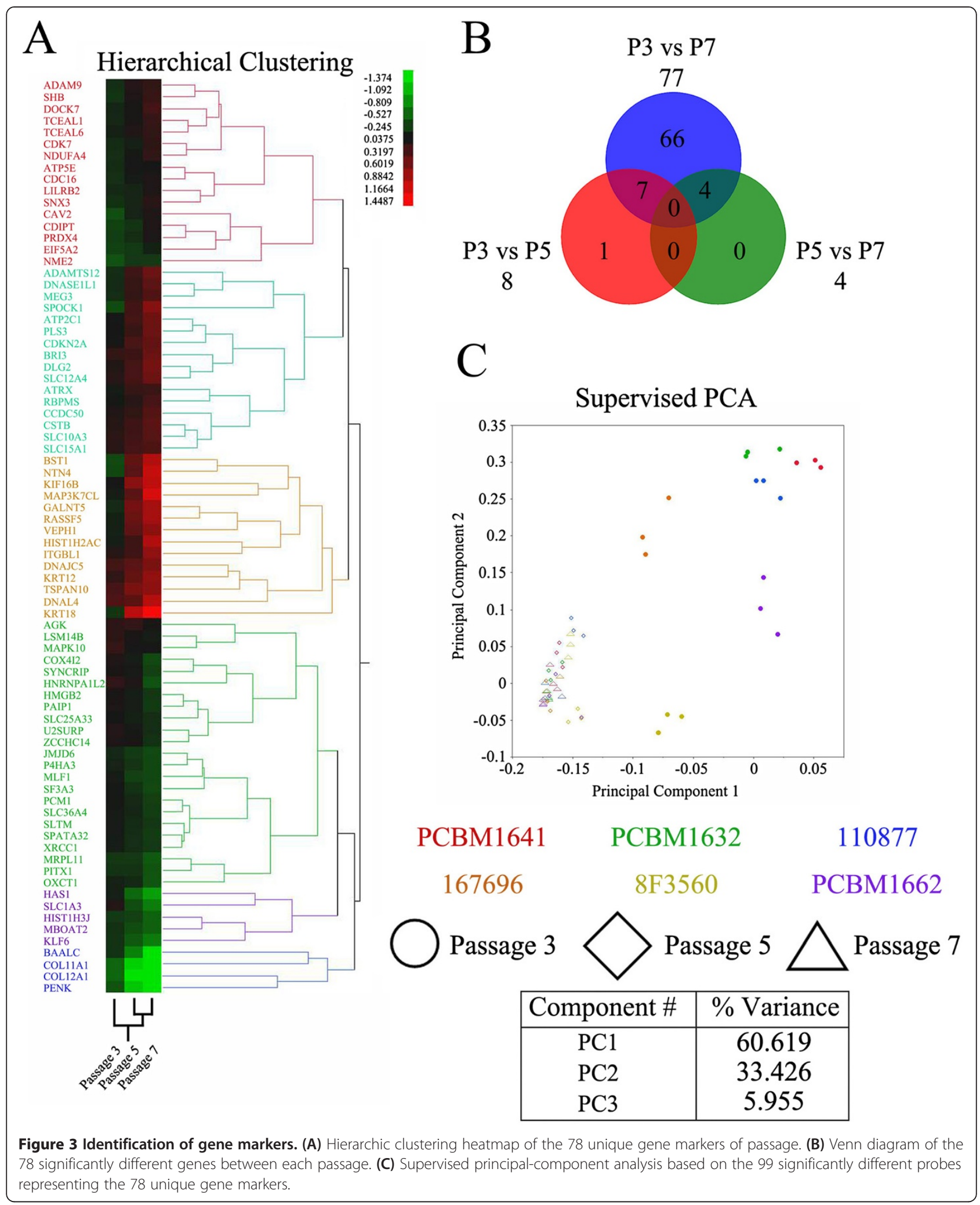

\section{Discussion}

Gene-expression profiling by microarray technology is an excellent high-throughput method for profiling whole- genome expression of genes in any cell type and allows assessment of changes in gene expression as cells are manipulated in culture. We performed gene-expression profiling 
Table 3 Ingenuity pathway analysis

\begin{tabular}{|c|c|c|c|}
\hline \multicolumn{4}{|c|}{ Molecular and cellular functions ${ }^{a}$} \\
\hline Function & $P$ value & $\begin{array}{l}\text { Number } \\
\text { of genes }\end{array}$ & Genes \\
\hline Cell death and survival & $\begin{array}{l}1.33 \times 10^{-4}- \\
4.52 \times 10^{-2}\end{array}$ & 15 & $\begin{array}{l}\uparrow A T P 2 C 1, \uparrow A T R X, \uparrow C D K 7, \uparrow C D K N 2 A, \uparrow D N A J C 5, \downarrow H M G B 2, \downarrow K L F 6, \uparrow K R T 18, \downarrow M A P K 10, \\
\uparrow N T N 4, \downarrow P E N K, \uparrow P R D X 4, \uparrow R A S S F 5, \downarrow S L C 1 A 3, \uparrow S P O C K 1\end{array}$ \\
\hline Cellular development & $\begin{array}{l}8.80 \times 10^{-4}- \\
4.89 \times 10^{-2}\end{array}$ & 21 & $\begin{array}{l}\downarrow A G K, \uparrow A T P 2 C 1, \uparrow B S T 1, \uparrow C A V 2, \uparrow C D C 16, \uparrow C D K N 2 A, \downarrow C O L 11 A 1, \uparrow D O C K 7, \uparrow E I F 5 A 2, \\
\downarrow H A S 1, \downarrow H M G B 2, \downarrow K L F 6, \uparrow M E G 3, \uparrow N M E 2^{*}, \uparrow N T N 4, \downarrow P C M 1, \downarrow P E N K, \downarrow P I T X 1, \uparrow R A S S F 5, \\
\uparrow S L C 12 A 4, \downarrow S L C 1 A 3,\end{array}$ \\
\hline Cellular growth and proliferation & $\begin{array}{l}8.80 \times 10^{-4}- \\
4.89 \times 10^{-2}\end{array}$ & 24 & $\begin{array}{l}\downarrow A G K, \uparrow C A V 2, \uparrow C D C 16, \uparrow C D K 7, \uparrow C D K N 2 A, \uparrow D O C K 7, \uparrow E I F 5 A 2, \downarrow H A S 1, \downarrow H M G B 2, \downarrow K L F 6, \\
\uparrow L I L R B 2, \downarrow M A P K 10, \uparrow M E G 3, \uparrow N M E 2^{*}, \uparrow N T N 4, \downarrow P E N K, \uparrow P R D X 4, \uparrow R A S S F 5, \downarrow S F 3 A 3, \uparrow S H B, \\
\uparrow S L C 12 A 4, \downarrow S L C 1 A 3, \uparrow S P O C K 1, \downarrow X R C C 1\end{array}$ \\
\hline Cell cycle & $\begin{array}{l}1.48 \times 10^{-3}- \\
4.52 \times 10^{-2}\end{array}$ & 12 & $\begin{array}{l}\uparrow A T R X, \downarrow A G K, \uparrow C D C 16, \uparrow C D K 7, \uparrow C D K N 2 A, \downarrow H A S 1, \downarrow K L F 6, \uparrow K R T 18, \downarrow M L F 1, \downarrow P C M 1, \\
\uparrow R A S S F 5, \uparrow S H B\end{array}$ \\
\hline Carbohydrate metabolism & $\begin{array}{l}3.85 \times 10^{-3} \\
2.82 \times 10^{-2}\end{array}$ & 5 & $\downarrow A G K, \uparrow C D I P T, \uparrow G A L N T 5, \downarrow H A S 1, \downarrow S L C 1 A 3$, \\
\hline \multicolumn{4}{|c|}{ Physiologic system development and function } \\
\hline Function & $P$ value & $\begin{array}{l}\text { Number } \\
\text { of genes }\end{array}$ & Genes \\
\hline $\begin{array}{l}\text { Respiratory system } \\
\text { Development and function }\end{array}$ & $\begin{array}{l}1.48 \times 10^{-3}- \\
1.91 \times 10^{-2}\end{array}$ & 3 & $\uparrow C A V 2, \uparrow C D K N 2 A, \downarrow P C M 1$ \\
\hline $\begin{array}{l}\text { Skeletal and muscular system } \\
\text { development and function }\end{array}$ & $\begin{array}{l}1.67 \times 10^{-3}- \\
4.89 \times 10^{-2}\end{array}$ & 9 & $\begin{array}{l}\uparrow C A V 2, \uparrow C D K N 2 A, \downarrow C O L 11 A 1, \downarrow C O L 12 A 1, \downarrow C O X 412, \uparrow D N A J C 5, \downarrow H M G B 2, \downarrow P I T X 1, \\
\downarrow S Y N C R I P\end{array}$ \\
\hline Tissue development & $\begin{array}{l}1.67 \times 10^{-3}- \\
4.89 \times 10^{-2}\end{array}$ & 16 & $\begin{array}{l}\uparrow A D A M 9, \uparrow A T P 2 C 1, \uparrow C D K N 2 A, \downarrow C O L 11 A 1, \downarrow C O L 12 A 1, \uparrow C S T B, \downarrow H A S 1, \downarrow H M G B 2, \\
\downarrow M M J D 6, \downarrow K L F 6, \uparrow K R T 18, \downarrow M A P K 10, \uparrow N M E 2^{*}, \uparrow N T N 4, \downarrow P I T X 1, \downarrow S L C 1 A 3\end{array}$ \\
\hline Embryonic development & $\begin{array}{l}2.15 \times 10^{-3}- \\
4.89 \times 10^{-2}\end{array}$ & 15 & $\begin{array}{l}\uparrow A T P 2 C 1, \uparrow C D K 7, \uparrow C D K N 2 A, \downarrow C O L 12 A 1, \uparrow C S T B, \uparrow D N A J C 5, \downarrow H M G B 2, \downarrow K L F 6, \uparrow K R T 18, \\
\uparrow N M E 2^{*}, \uparrow N T N 4, \downarrow P I T X 1, \uparrow S H B, \downarrow S L C 1 A 3, \downarrow X R C C 1\end{array}$ \\
\hline Organ development & $\begin{array}{l}2.15 \times 10^{-3}- \\
4.89 \times 10^{-2}\end{array}$ & 13 & $\begin{array}{l}\uparrow A D A M 9, \uparrow A T P 2 C 1, \uparrow C D K N 2 A, \downarrow C O L 12 A 1, \uparrow C S T B, \uparrow D N A J C 5, \downarrow H M G B 2, \downarrow K L F 6, \uparrow K R T 18, \\
\uparrow N M E 2^{*}, \uparrow N T N 4, \downarrow P I T X 1, \downarrow S L C 1 A 3\end{array}$ \\
\hline
\end{tabular}

List of genes (up- or downregulated) involved in top functions. Fisher Exact Test was used by IPA to calculate the range of $P$ values. $\uparrow$ upregulated, $\downarrow$ downregulated, *Not significant between passages 3 and 7.

of human bone marrow-derived MSCs as they are passaged in cell culture. By highly robust statistical analysis, we discovered that 99 statistically significant probes changed expression as a result of time in cell culture. These 99 probes represented 81 unique genes that were significantly different between at least two different passages, of which 78 are known, and three have not been classified. We previously reported that these MSCs showed similar phenotypes at passages 3 and 7, despite gene-expression changes. In addition, MSCs from two different vendors exhibited uniform changes in gene expression.

For gene markers that can accurately indicate quality of MSCs in culture, markers should show a consistent pattern over time, such as an up- or downregulation, in comparison with an early time point. Genes with a temporal change in expression where expression at P5 is significantly different with P3; however, expression between P3 and P7 is not significant, and would not make an ideal gene marker. Instead, a gene marker with a significant difference between P3 and P7 would be a better predictor of MSC quality. Our filtering methods ensured that sensitivity issues (Figure 3A) and donor variation (Figure $3 \mathrm{~B}$ ) would not obscure results by eliminating genes from the dataset where expression differences between passage 3 and 7 were highly variable and not reproducible.

Combined with our multiplicity adjustment methods, we were also able to exclude genes whose statistical significance was likely due to chance. With these analytic techniques, we identified three clusters of genes that exhibited upregulation from passages 3 to 7 , whereas another three clusters exhibited downregulation from passages 3 to 7 .

Previous investigations have executed similar studies involving gene-expression profiling of human MSCs derived from bone marrow with long-term culture. Kulterer et al. reported that 838 genes were differentially expressed between P2 and P5, with 10 of those genes matching those identified in our study (Table 2) (BST1, COL11A1, COL12A1, GALNT5, HAS1, KRT18, MEG3, $P C M 1, P E N K$, and $S H B$ ) [48]. Likewise, in another study by Tanabe et al., two genes reported matched those found in our study (KRT18 and PRDX4) [49]. A number of reasons exist for the discrepancies from a biologic standpoint, including culture conditions, media used, and the source of MSCs; however, poor experimental design and statistical analysis are the primary sources for misleading results. Ren et al. [50] examined the effects of cell 

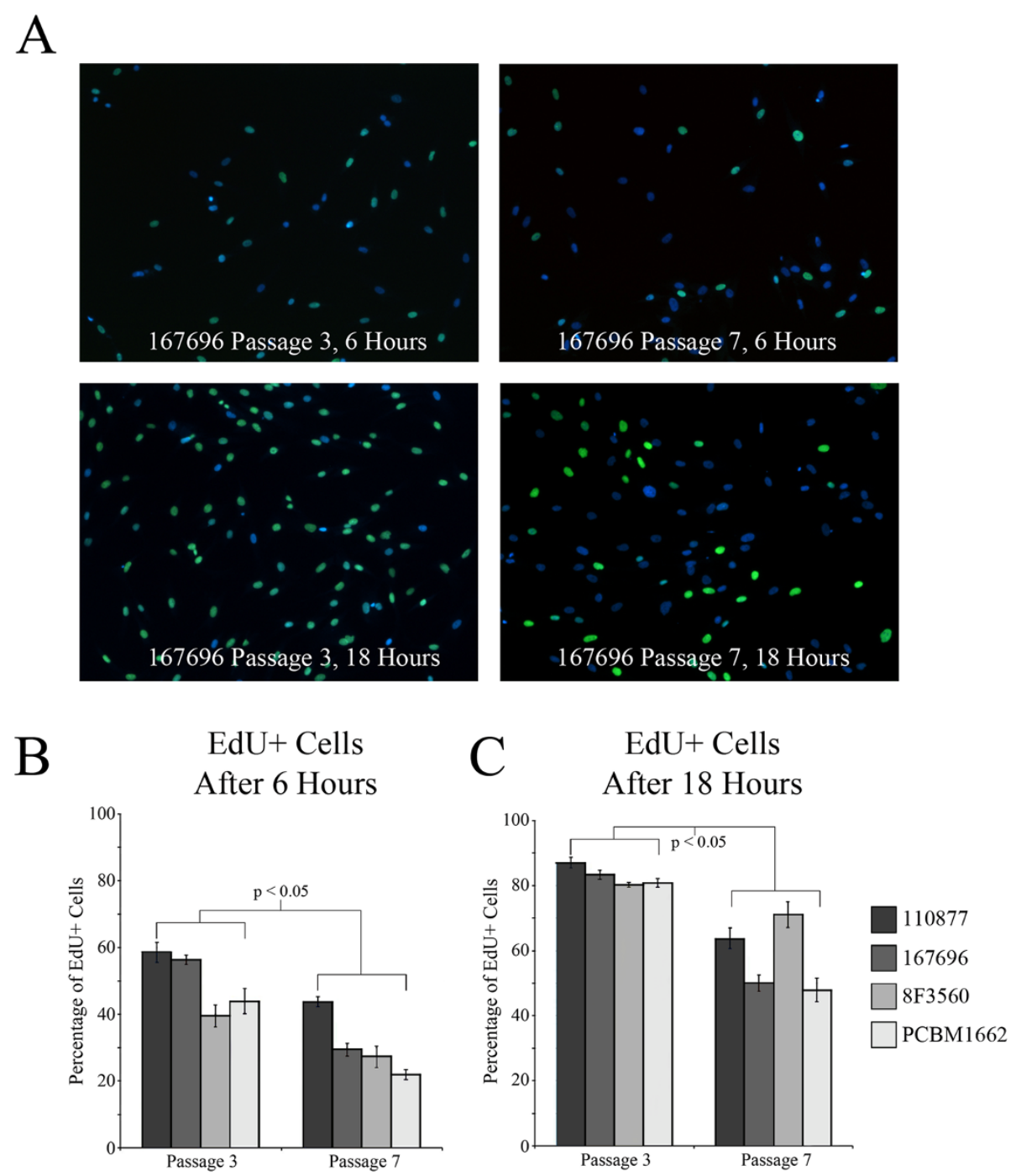

Figure 4 Analysis of MSC proliferation at passages 3 and 7. (A) The percentage of EdU-positive cells was determined for four different donors after both 6 and 18 hours at passages 3 and 7 (EdU, green; nuclei, blue). (B) A paired $t$ test indicated a statistically significant difference $(P<0.05)$ between passages 3 and 7 for EdU-positive expression at 6 hours. (C) A paired $t$ test indicated a statistically significant difference between passages 3 and 7 for EdU-positive expression at 18 hours.

aging on gene expression by categorizing samples by the degree of senescence in contrast to passage. This study used a highly robust statistical analysis, which identified 15 statistically significant genes (ADAMTS12, BAALC, BST1, CAV2, CDKN2A, COL11A1, COL12A1, DNASE1L1, EIF5A2, GALNT5, KRT18, MEG3, NTN4, SLC1A3, and $V E P H 1)$ that were identical to our gene list with the same up-/downregulation compared with early passages. The magnitude of fold change was also typically greater than the magnitude of fold change reported in our own results, and this may be due to Ren et al. carrying out cell cultures to a higher passage number. This suggests that minute differences in gene expression detected between closely related passages increases with more-distant passages or cellular aging.
Approximately $37 \%$ of the 78 gene markers imported into IPA were observed to have some function related to cellular growth and proliferation and cellular development. Two of the 78 different marker genes belong to the keratin family, KRT12 and KRT18, in which significant gene-expression changes were observed in multiple publications [48-50]. Keratins are fibrous structural proteins that play a major functional role in the integrity and mechanical stability of epithelial tissues [51]. Typically, keratins are observed in pairs such as KRT18 and KRT8, which are co-expressed in simple epithelium. As indicated in IPA (Table 3), keratins are strongly connected to the functions of cell cycle and cell death and survival, which can profoundly affect cellular development. Increases in keratin expression are particularly observed 
with the progression of cell differentiation in keratinocytes or in organs such as the pancreas or liver [52-56]. Sixteen different sequences representing the KRT18 gene on these microarray chips were upregulated at passage 7 compared with passage 3. KRT18 expression has also been suggested to play a role in the immunosuppressive potential of graftversus-host disease (GVHD). KRT18 expression, as measured by serum fragments, was found to be elevated in lower gastrointestinal tract and liver GVHD [57,58]. Immunosuppressive therapy for GVHD resulted in decreases of KRT18 serum fragments.

Like KRT18, NTN4, a laminin-related secreted molecule protein exhibited more than a twofold upregulation in gene expression from passages 3 to 7. Studies suggests that NTN4 expression is tied to decreases in cell proliferation, as has been observed in corneal and pancreatic epithelium, as well as in a human breast cancer cell line (MCF7) [59-61]. However, conflicting arguments have been made about the function of NTN4, as it has been observed to promote cell proliferation in various tumor cell types [62-64]. Similarly, BST1, bone marrow stromal cell antigen 1, was observed to have a 2.46-fold change from passages 3 to 7 . It is a stromal cell line-derived glycosylphosphatidylinositol-anchored molecule that has been identified to facilitate pre-B-cell maturation based on its enhanced expression in rheumatoid arthritis-derived bone marrow stromal cell lines and activation by Pax5 [65-67]. An increase in BST1 expression has been observed in several studies with aging in culture, in which elevated expression levels have been tied to nonneurogenesis-promoting astrocytes $[48,68,69]$.

The gene that exhibited the greatest change in expression from passages 3 to 7 was $P E N K$, which was downregulated 4.15 fold. PENK is an endogenous opioid polypeptide hormone found at high levels in the brain and endocrine tissues [70]. They typically function as neurotransmitters to modulate pain, cellular growth, organogenesis, and immunity, because they are also widely observed in nonneuronal tissues [71]. PENK expression, known in early neuronal development, was observed to be upregulated in neuron-like differentiated bone marrowderived MSCs compared with undifferentiated MSCs [72]. Likewise, SYNCRIP, which was downregulated from passages 3 to 7 by 1.24 fold, has been involved in neuronal synaptic transmission and was also exhibited to be upregulated in neurogenic differentiated MSCs. PENK expression has also been linked to osteoblastic development, in which decreases in PENK paralleled decreases in osteogenic differentiation, as measured alkaline phosphatase activity $[73,74]$. A later study has indicated that may not be true for in vivo experiments as PENK-deficient mice did not exhibit a difference in bone remodeling compared with wild-type littermates unless PENK expression was deleted from Phex-deficient Hyp mice [75].
Another gene typically involved with the developing central and peripheral nervous systems expressed to enhance growth is KLF6 [76]. KLF6 is known as a zincfinger DNA-binding transcription factor regulating gene expression and was downregulated from passages 3 to 7 by -1.43 . Two different studies examining KLF6 in mice found that their expression affects neuronal morphogenesis by promoting axon outgrowth [77,78]. Furthermore, KLF6 expression was observed to regulate proliferation and differentiation positively as KLF6-/- ES cells demonstrated significant defects after differentiation into embryoid bodies.

Like PENK, BAALC exhibited a 2.33-fold downregulation from passages 3 to 7. BAALC is an overexpressed gene usually found in a subset of patients with acute myeloid leukemia within neuroectoderm-derived and mesoderm tissues $[79,80]$. Its expression has also been observed in early hematopoietic progenitor cells, in which its subsequent loss is associated with cell differentiation [81]. Because the expression of BAALC was dramatically reduced with increasing passage, this suggests the MSCs lose their multipotent potential as they aged in culture. Two genes associated with fibril elongation, COL11A1 and COL12A1, were also observed to be downregulated with increasing passage more than twofold. Elevated levels of expression are observed for both genes in response to different cell-proliferative assays. In hyalocytes, ascorbic acid was observed to increase their proliferation in combination with increasing COL11A1 expression, whereas in a different study, chondrocytes exhibited high-density micromass growth in conjunction with $C O L 11 A 1[82,83]$. Similarly, COL12A1 was upregulated with the growth of glioblastoma multiforme compared with normal brain, and when the proliferative potential of SKOV3 cells was reduced by knocking down the expression of RUNX1, COL12A1 expression also decreased $[84,85]$. Other studies have also indicated that an elevated level of expression leads to osteoblast differentiation and maturation, whereas their suppression can terminate this process [86-88]. In our study, the decrease in both collagens with passaging suggests a reduced capacity for osteogenic differentiation or limited MSC multipotency.

The gene markers presented in this study allude to MSC senescence and unwanted differentiation that can often go unnoticed with passage. Multiple studies have demonstrated that MSCs exhibit a reduction in cellular proliferation with culture, which is consistent with our current work when these identical donors were evaluated $[35,39,89]$. Our previous studies examining these same donors exhibited increases in cell size with length in culture by flow cytometry and automated cell counting $[39,47]$.

Furthermore, our prior work investigating the multipotency of these MSCs illustrated a decreased percentage of 
colony-forming units and a reduced potential for adipogenic differentiation, as observed by the percentage of Nile red-positive cells [39,47]. Rather than using bioassays to determine MSC quality during passaging and cell expansion, future work may establish quality through the expression of a set of gene or protein markers. Based on these results, MSCs performance is most likely best at earlier passages of culturing. The conglomerate of these gene markers exhibiting altered gene expression at passage 7 suggests that they are undergoing terminal differentiation that is comparable with reaching cellular senescence. This can negatively affect potential therapeutic applications in which the transplantation of aged cells can send detrimental signals leading to erroneous regeneration or prevent immunosuppression. Extreme caution should be considered when using the ISCT markers for MSC characterization, as they are commonly used as quality markers when generating criteria for lot release with respect to MSC identity and purity [90]. Despite the use of ISCT markers to establish purity of an MSC population, heterogeneity and diminished performance persist with continuous culturing, whereas ISCT marker expression remains consistent [47]. Our prior and current results indicate significant changes in MSC performance through biologic assays and gene expression; thus the identified gene markers may be useful in producing quality markers of cellular aging over successive rounds of passaging.

Additional work is necessary to determine whether the expression of identified gene markers is consistently modulated when cellular expansion is scaled up by using bioreactors or performed with different substrates and media components. Discovering genes expressed in MSCs that correlate with a functional outcome will provide a basis for a set of quality markers. These quality markers can then be used to assess cellular products desired for a specific application. These are major considerations in establishing quality, function, and safety of MSCs for therapeutic purposes.

\section{Conclusions}

An increasing interest exists in determining markers that can be used to distinguish between different donors and culture conditions of MSCs. As MSCs are aged in culture, they begin to exhibit gene-expression changes related to cell growth and proliferation, cell survival, and cellular development as observed through reduced cellular proliferation at a higher passage. Reproducible geneexpression changes were consistently detected among different MSC donors. Results obtained from these studies may provide insights into MSC differentiation and function with passaging in culture.

\section{Additional file}

Additional file 1: Figure S1. Outline of the major topics and interrelated steps used to analyze microarray data. (1) Experimental design, (2) normalization, (3) gene filter, (4) statistical analysis, and (5) pathway analysis.

\section{Abbreviations}

aMEM: alpha-Minimum essential media; ANOVA: analysis of variance; FBS: fetal bovine serum; GVHD: graft-versus-host disease; IPA: ingenuity pathway analysis; ISCT: International Society for Cellular Therapy; MSC: multipotent stromal cell.

\section{Competing interests}

The authors declare that they have no competing interests.

\section{Authors' contributions}

IHB was involved in the experimental conception and design, data acquisition, data analysis, interpretation, and drafting/revising the manuscript for important intellectual content. JGC was involved in the experimental conception and design, data analysis, interpretation, and drafting/revising the manuscript for important intellectual content. SL performed data analysis and drafting/revising of the manuscript for important intellectual content. $A X Y$ was involved in microarray platform manufacturing, data acquisition, and drafting/revising the manuscript for important intellectual content. JLL was involved in sample preparation, data acquisition and drafting/revising the manuscript for important intellectual content. SRB was involved in conception, design, data acquisition, and drafting/revising the manuscript for important intellectual content. RKP was involved in the conception and design, interpretation, and drafting/revising the manuscript for important intellectual content. All authors read and approved the final version of this manuscript, and agree to be accountable for all aspects of the work in ensuring that questions related to the accuracy or integrity of any part of the work are appropriately investigated and resolved.

\section{Acknowledgements}

This project was supported in part by an appointment of lan Bellayr to the Research Participation Program at the Center for Biologics Evaluation and Research administered by the Oak Ridge Institute for Science and Education through an interagency agreement between the U.S. Department of Energy and the U.S. Food and Drug Administration. This project was also supported by the Medical Countermeasures Initiative and the FDA Modernizing Science Initiative. We thank the members of the FDA Modernizing Science Consortium for their discussion of the presented work, in addition to Drs. Brenton McCright and Shyh-Ching Lo for reviewing the manuscript.

\section{Author details}

${ }^{1}$ Tumor Vaccines and Biotechnology Branch, Division of Cellular and Gene Therapies, Center for Biologics and Evaluation Research, US Food and Drug Administration, Bethesda, MD, USA. ${ }^{2}$ Office of Biostatistics and Epidemiology, Center for Biologics and Evaluation Research, US Food and Drug

Administration, Rockville, MD, USA. ${ }^{3}$ Cellular and Tissue Therapies Branch, Division of Cellular and Gene Therapies, Center for Biologics Evaluation and Research, US Food and Drug Administration, Bethesda, MD, USA.

Received: 8 January 2014 Revised: 18 February 2014 Accepted: 15 April 2014 Published: 28 April 2014

\section{References}

1. Liu Y, Goldberg AJ, Dennis JE, Gronowicz GA, Kuhn LT: One-step derivation of mesenchymal stem cell (MSC)-like cells from human pluripotent stem cells on a fibrillar collagen coating. PLoS One 2012, 7:e33225.

2. Caplan Al, Dennis JE: Mesenchymal stem cells as trophic mediators. J Cell Biochem 2006, 98:1076-1084.

3. Patel AN, Park E, Kuzman M, Benetti F, Silva FJ, Allickson JG: Multipotent menstrual blood stromal stem cells: isolation, characterization, and differentiation. Cell Transplant 2008, 17:303-311.

4. The National Institute of Health Clinical Trials. [http://www.clinicaltrials.gov/] 
5. Lau D, Ogbogu U, Taylor B, Stafinski T, Menon D, Caulfield T: Stem cell clinics online: the direct-to-consumer portrayal of stem cell medicine. Cell Stem Cell 2008, 3:591-594.

6. Andriamanalijaona R, Duval E, Raoudi M, Lecourt S, Vilquin JT, Marolleau JP, Pujol JP, Galera P, Boumediene K: Differentiation potential of human muscle-derived cells towards chondrogenic phenotype in alginate beads culture. Osteoarthritis Cartilage 2008, 16:1509-1518.

7. Riekstina U, Cakstina I, Parfejevs V, Hoogduijn M, Jankovskis G, Muiznieks I, Muceniece R, Ancans J: Embryonic stem cell marker expression pattern in human mesenchymal stem cells derived from bone marrow, adipose tissue, heart and dermis. Stem Cell Rev 2009, 5:378-386.

8. Du Y, Roh DS, Funderburgh ML, Mann MM, Marra KG, Rubin JP, Li X, Funderburgh JL: Adipose-derived stem cells differentiate to keratocytes in vitro. Mol Vis 2010, 16:2680-2689.

9. De la Fuente A, Mateos J, Lesende-Rodriguez I, Calamia V, Fuentes-Boquete I, de Toro FJ, Arufe MC, Blanco FJ: Proteome analysis during chondrocyte differentiation in a new chondrogenesis model using human umbilical cord stroma mesenchymal stem cells. Mol Cell Proteom 2012, 11:010496.

10. Barradas AM, Fernandes HA, Groen N, Chai YC, Schrooten J, van de Peppel J, van Leeuwen JP, van Blitterswijk CA, de Boer J: A calcium-induced signaling cascade leading to osteogenic differentiation of human bone marrow-derived mesenchymal stromal cells. Biomaterials 2012, 33:3205-3215.

11. Kim J, Kang JW, Park JH, Choi Y, Choi KS, Park KD, Baek DH, Seong SK, Min HK, Kim HS: Biological characterization of long-term cultured human mesenchymal stem cells. Arch Pharm Res 2009, 32:117-126.

12. Rossignoli F, Caselli A, Grisendi G, Piccinno S, Burns JS, Murgia A, Veronesi E, Loschi P, Masini C, Conte P, Paolucci P, Horwiz EM, Dominici M: Isolation, characterization, and transduction of endometrial decidual tissue multipotent mesenchymal stromal/stem cells from menstrual blood. Biomed Res Int 2013, 2013:901821.

13. Dominici M, Le Blanc K, Mueller I, Slaper-Cortenbach I, Marini F, Krause D, Deans R, Keating A, Prockop D, Horwitz E: Minimal criteria for defining multipotent mesenchymal stromal cells: The International Society for Cellular Therapy position statement. Cytotherapy 2006, 8:315-317.

14. Cutler AJ, Limbani V, Girdlestone J, Navarrete CV: Umbilical cord-derived mesenchymal stromal cells modulate monocyte function to suppress $T$ cell proliferation. J Immunol 2010, 185:6617-6623.

15. Arufe MC, De la Fuente A, Fuentes J, Mateos I, De Toro FJ, Blanco FJ: Analysis of the chondrogenic potential and secretome of mesenchymal stem cells derived from human umbilical cord stroma. Stem Cells Dev 2011, 20:1199-1212.

16. Maurer MH: Proteomic definitions of mesenchymal stem cells. Stem Cells Int 2011, 2011:704256.

17. Ren G, Zhang L, Zhao X, Xu G, Zhang Y, Roberts Al, Zhao RC, Shi Y: Mesenchymal stem cell-mediated immunosuppression occurs via concerted action of chemokines and nitric oxide. Cell Stem Cell 2008 2:141-150.

18. Hermann A, Liebau S, Gastl R, Fickert S, Habisch HJ, Fiedler J, Schwarz J, Brenner R, Storch A: Comparative analysis of neuroectodermal differentiation capacity of human bone marrow stromal cells using various conversion protocols. J Neurosci Res 2006, 83:1502-1514.

19. Alaimo G, Cozzoli E, Marfe G, Esposito L, Ranalli M, Hmada D, Giordano A, Gambacurta A: Blood-derived stem cells (BDSCs) plasticity: in vitro hepatic differentiation. J Cell Physiol 2012, 228:1249-1254.

20. Jankowski RJ, Haluszczak C, Trucco M, Huard J: Flow cytometric characterization of myogenic cell populations obtained via the preplate technique: potential for rapid isolation of muscle-derived stem cells. Hum Gene Ther 2001, 12:619-628.

21. Ishimura D, Yamamoto N, Tajima K, Ohno A, Yamamoto Y, Washimi O, Yamada $\mathrm{H}$ : Differentiation of adipose-derived stromal vascular fraction culture cells into chondrocytes using the method of cell sorting with a mesenchymal stem cell marker. Tohoku J Exp Med 2008, 216:149-156.

22. Griesche N, Luttmann W, Luttmann A, Stammermann T, Geiger H, Baer PC: A simple modification of the separation method reduces heterogeneity of adipose-derived stem cells. Cells Tissues Organs 2010, 192:106-115.

23. Jansen BJ, Gilissen C, Roelofs H, Schaap-Oziemlak A, Veltman JA, Raymakers RA, Jansen JH, Kogler G, Figdor CG, Torensma R, Adema GJ: Functional differences between mesenchymal stem cell populations are reflected by their transcriptome. Stem Cells Dev 2010, 19:481-490.
24. Rebelatto CK, Aguiar AM, Moretao MP, Senegaglia AC, Hansen P, Barchiki F, Oliveira J, Martins J, Kuligovski C, Mansur F, Christofis A, Amaral VF, Brofman PS, Goldenberg S, Nakao LS, Correa A: Dissimilar differentiation of mesenchymal stem cells from bone marrow, umbilical cord blood, and adipose tissue. Exp Biol Med (Maywood) 2008, 233:901-913

25. Wagner W, Wein F, Seckinger A, Frankhauser M, Wirkner U, Krause U, Blake J, Schwager C, Eckstein V, Ansorge W, Ho AD: Comparative characteristics of mesenchymal stem cells from human bone marrow, adipose tissue, and umbilical cord blood. Exp Hematol 2005, 33:1402-1416.

26. Secco M, Moreira YB, Zucconi E, Vieira NM, Jazedje T, Muotri AR, Okamoto OK, Verjovski-Almeida S, Zatz M: Gene expression profile of mesenchymal stem cells from paired umbilical cord units: cord is different from blood. Stem Cell Rev 2009, 5:387-401.

27. Phinney DG, Kopen G, Righter W, Webster S, Tremain N, Prockop DJ: Donor variation in the growth properties and osteogenic potential of human marrow stromal cells. J Cell Biochem 1999, 75:424-436.

28. Phinney DG, Kopen G, Isaacson RL, Prockop DJ: Plastic adherent stromal cells from the bone marrow of commonly used strains of inbred mice: variations in yield, growth, and differentiation. J Cell Biochem 1999, 72:570-585.

29. Muraglia A, Cancedda R, Quarto R: Clonal mesenchymal progenitors from human bone marrow differentiate in vitro according to a hierarchical model. J Cell Sci 2000, 113:1161-1166.

30. Guilak F, Lott KE, Awad HA, Cao Q, Hicok KC, Fermor B, Gimble JM: Clonal analysis of the differentiation potential of human adipose-derived adult stem cells. J Cell Physiol 2006, 206:229-237.

31. Schellenberg A, Stiehl T, Horn P, Joussen S, Pallua N, Ho AD, Wagner W: Population dynamics of mesenchymal stromal cells during culture expansion. Cytotherapy 2012, 14:401-411.

32. Kim M, Kim C, Choi YS, Park C, Suh Y: Age-related alterations in mesenchymal stem cells related to shift in differentiation from osteogenic to adipogenic potential: implication to age-associated bone diseases and defects. Mech Ageing Dev 2012, 133:215-225.

33. Khoo ML, Shen B, Tao H, Ma DD: Long-term serial passage and neuronal differentiation capability of human bone marrow mesenchymal stem cells. Stem Cells Dev 2008, 17:883-896.

34. Parsch D, Fellenberg J, Brummendorf TH, Eschlbeck AM, Richter W Telomere length and telomerase activity during expansion and differentiation of human mesenchymal stem cells and chondrocytes. J Mol Med (Berl) 2004, 82:49-55.

35. Wagner W, Bork S, Lepperdinger G, Joussen S, Ma N, Strunk D, Koch C: How to track cellular aging of mesenchymal stromal cells? Aging (Albany NY) 2010, 2:224-230.

36. Wagner W, Horn P, Castoldi M, Diehlmann A, Bork S, Saffrich R, Benes V, Blake J, Pfister S, Eckstein V, Ho AD: Replicative senescence of mesenchymal stem cells: a continuous and organized process. PLOS One 2008, 3:e2213.

37. Baer PC, Geiger H: Adipose-derived mesenchymal stromal/stem cells: tissue localization, characterization, and heterogeneity. Stem Cells Int 2012, 2012:812693.

38. Pevsner-Fischer M, Levin S, Zipori D: The origins of mesenchymal stromal cell heterogeneity. Stem Cell Rev 2011, 7:560-568.

39. Lo Surdo J, Bauer SR: Quantitative approaches to detect donor and passage differences in adipogenic potential and clonogenicity in human bone marrow-derived mesenchymal stem cells. Tissue Eng Part C Methods 2012, 18:877-889.

40. Bhattacharya B, Miura T, Brandenberger R, Mejido J, Luo Y, Yang AX, Joshi BH, Ginis I, Thies RS, Amit M, Lyons I, Condie BG, Itskovitz-Eldor J, Rao MS, Puri RK: Gene expression in human embryonic stem cell lines: unique molecular signature. Blood 2004, 103:2956-2964.

41. Han J, Lee H, Nguyen NY, Beaucage SL, Puri RK: Novel multiple 5'-aminomodified primer for DNA microarrays. Genomics 2005, 86:252-258.

42. Fang H, Harris SC, Su Z, Chen M, Qian F, Shi L, Perkins R, Tong W: ArrayTrack: an FDA and public genomic tool. Methods Mol Biol 2009, 563:379-398.

43. Bryant PA, Smyth GK, Robins-Browne R, Curtis N: Technical variability is greater than biological variability in a microarray experiment but both are outweighed by changes induced by stimulation. PLoS One 2011, 6:e19556

44. Benjamini $Y$, Hochberg $Y$ : Controlling the false discovery rate: a practical and powerful approach to multiple testing. J R Stat Soc Series B-Method 1995, 57:289-300. 
45. Dalman MR, Deeter A, Nimishakavi G, Duan ZH: Fold change and p-value cutoffs significantly alter microarray interpretations. BMC Bioinformat 2012, 13:S11.

46. Mutch DM, Berger A, Mansourian R, Rytz A, Roberts MA: Microarray data analysis: a practical approach for selecting differentially expressed genes. Genome Biol 2001, 2:PREPRINT0009.

47. Lo Surdo JL, Millis BA, Bauer SR: Automated microscopy as a quantitative method to measure differences in adipogenic differentiation in preparations of human mesenchymal stromal cells. Cytotherapy 2013, 15:1527-1540.

48. Kulterer B, Friedl G, Jandrositz A, Sanchez-Cabo F, Prokesch A, Paar C, Scheideler M, Windhager R, Preisegger KH, Trajanoski Z: Gene expression profiling of human mesenchymal stem cells derived from bone marrow during expansion and osteoblast differentiation. BMC Genom 2007, 8:70.

49. Tanabe S, Sato Y, Suzuki T, Suzuki K, Nagao T, Yamaguchi T: Gene expression profiling of human mesenchymal stem cells for identification of novel markers in early- and late-stage cell culture. J Biochem 2008, 144:399-408.

50. Ren J, Stroncek DF, Zhao Y, Jin P, Castiello L, Civini S, Wang H, Feng J, Tran K, Kuznetsov SA, Robey PG, Sabatino M: Intra-subject variability in human bone marrow stromal cell (BMSC) replicative senescence: molecular changes associated with BMSC senescence. Stem Cell Res 2013, 11:1060-1073.

51. Moll R, Divo M, Langbein L: The human keratins: biology and pathology. Histochem Cell Biol 2008, 129:705-733

52. Bisgaard HC, Ton PT, Nagy P, Thorgeirsson SS: Phenotypic modulation of keratins, vimentin, and alpha-fetoprotein in cultured rat liver epithelial cells after chemical, oncogene, and spontaneous transformation. J Cell Physiol 1994, 159:485-494.

53. Bouwens L: Cytokeratins and cell differentiation in the pancreas. J Pathol 1998, 184:234-239.

54. Chen X, Whitney EM, Gao SY, Yang WW: Transcriptional profiling of Kruppel-like factor 4 reveals a function in cell cycle regulation and epithelial differentiation. J Mol Biol 2003, 326:665-677.

55. Clausen H, Vedtofte P, Moe D, Dabelsteen E, Sun T, Dale B: Differentiationdependent expression of keratins in human oral epithelia. J Invest Dermatol 1986, 86:249-254.

56. Eckert RL, Rorke EA: Molecular biology of keratinocyte differentiation. Environ Health Perspect 1989, 80:109-116.

57. Luft T, Conzelmann M, Benner A, Rieger M, Hess M, Strohhaecker U, Gorner M, Hegenbart U, Ho AD, Dreger P: Serum cytokeratin-18 fragments as quantitative markers of epithelial apoptosis in liver and intestinal graft-versus-host disease. Blood 2007, 110:4535-4542.

58. Harris AC, Ferrara JL, Braun TM, Holler E, Teshima T, Levine JE, Choi SW, Landfried K, Akashi K, Vander Lugt M, Couriel DR, Reddy P, Paczesny S: Plasma biomarkers of lower gastrointestinal and liver acute GVHD. Blood 2012, 119:2960-2963.

59. Fujikane T, Nishikawa N, Toyota M, Suzuki H, Nojima M, Maruyama R, Ashida M, Ohe-Toyota M, Kai M, Nishidate T, Sasaki Y, Ohmura T, Hirata K, Tokino T: Genomic screening for genes upregulated by demethylation revealed novel targets of epigenetic silencing in breast cancer. Breast Cancer Res Treat 2010, 122:699-710.

60. Li YN, Pinzon-Duarte G, Dattilo M, Claudepierre T, Koch M, Brunken WJ: The expression and function of netrin- 4 in murine ocular tissues. Exp Eye Res 2012, 96:24-35.

61. Yebra M, Diaferia GR, Montgomery AM, Kaido T, Brunken WJ, Koch M, Hardiman G, Crisa L, Cirulli V: Endothelium-derived Netrin-4 supports pancreatic epithelial cell adhesion and differentiation through integrins alpha2beta1 and alpha3beta1. PLoS One 2011, 6:e22750.

62. Eveno C, Broqueres-You D, Feron JG, Rampanou A, Tijeras-Raballand A, Ropert S, Leconte L, Levy BI, Pocard M: Netrin-4 delays colorectal cancer carcinomatosis by inhibiting tumor angiogenesis. Am J Pathol 2011, 178:1861-1869.

63. Hu Y, Ylivinkka I, Chen P, Li L, Hautaniemi S, Nyman TA, Keski-Oja J, Hyytiainen M: Netrin-4 promotes glioblastoma cell proliferation through integrin beta4 signaling. Neoplasia 2012, 14:219-227.

64. Nacht M, St Martin TB, Byrne A, Klinger KW, Teicher BA, Madden SL, Jiang Y: Netrin-4 regulates angiogenic responses and tumor cell growth. Exp Cell Res 2009, 315:784-794.

65. Kaisho T, Ishikawa J, Oritani K, Inazawa J, Tomizawa H, Muraoka O, Ochi T, Hirano T: BST-1, a surface molecule of bone marrow stromal cell lines that facilitates pre-B-cell growth. Proc Natl Acad Sci U S A 1994, 91:5325-5329.

66. Itoh M, Ishihara $K$, Hiroi $T$, Lee BO, Maeda H, lijima H, Yanagita M, Kiyono $H$, Hirano T: Deletion of bone marrow stromal cell antigen-1 (CD157) gene impaired systemic thymus independent-2 antigen-induced IgG3 and mucosal TD antigen-elicited IgA responses. J Immunol 1998, 161:3974-3983

67. Pridans C, Holmes ML, Polli M, Wettenhall JM, Dakic A, Corcoran LM, Smyth GK, Nutt SL: Identification of Pax5 target genes in early B cell differentiation. J Immunol 2008, 180:1719-1728.

68. Barkho BZ, Song H, Aimone JB, Smrt RD, Kuwabara T, Nakashima K, Gage $\mathrm{FH}$, Zhao $\mathrm{X}$ : Identification of astrocyte-expressed factors that modulate neural stem/progenitor cell differentiation. Stem Cells Dev 2006, 15:407-421.

69. Shahdadfar A, Fronsdal K, Haug T, Reinholt FP, Brinchmann JE: In vitro expansion of human mesenchymal stem cells: choice of serum is a determinant of cell proliferation, differentiation, gene expression, and transcriptome stability. Stem Cells 2005, 23:1357-1366.

70. Hafizi M, Bakhshandeh B, Soleimani M, Atashi A: Exploring the enkephalinergic differentiation potential in adult stem cells for cell therapy and drug screening implications. In Vitro Cell Dev Biol Anim 2012, 48:562-569.

71. Denning GM, Ackermann LW, Barna TJ, Armstrong JG, Stoll LL, Weintraub NL, Dickson EW: Proenkephalin expression and enkephalin release are widely observed in non-neuronal tissues. Peptides 2008, 29:83-92.

72. Tondreau T, Dejeneffe M, Meuleman N, Stamatopoulos B, Delforge A, Martiat $P$, Bron D, Lagneaux L: Gene expression pattern of functional neuronal cells derived from human bone marrow mesenchymal stromal cells. BMC Genomics 2008, 9:166.

73. Rosen H, Krichevsky A, Polakiewicz RD, Benzakine S, Bar-Shavit Z Developmental regulation of proenkephalin gene expression in osteoblasts. Mol Endocrinol 1995, 9:1621-1631.

74. Rosen H, Krichevsky A, Bar-Shavit Z: The enkephalinergic osteoblast. J Bone Miner Res 1998, 13:1515-1520.

75. Seitz S, Barvencik F, Gebauer M, Albers J, Schulze J, Streichert T, Amling M, Schinke T: Preproenkephalin (Penk) is expressed in differentiated osteoblasts, and its deletion in Hyp mice partially rescues their bone mineralization defect. Calcif Tissue Int 2010, 86:282-293.

76. Moore DL, Apara A, Goldberg JL: Kruppel-like transcription factors in the nervous system: novel players in neurite outgrowth and axon regeneration. Mol Cell Neurosci 2011, 47:233-243.

77. Laub F, Lei L, Sumiyoshi H, Kajimura D, Dragomir C, Smaldone S, Puche AC, Petros TJ, Mason C, Parada LF, Ramirez F: Transcription factor KLF7 is important for neuronal morphogenesis in selected regions of the nervous system. Mol Cell Biol 2005, 25:5699-5711.

78. Matsumoto N, Kubo A, Liu H, Akita K, Laub F, Ramirez F, Keller G, Friedman SL: Developmental regulation of yolk sac hematopoiesis by Kruppel-like factor 6. Blood 2006, 107:1357-1365.

79. Tanner SM, Austin JL, Leone G, Rush LJ, Plass C, Heinonen K, Mrozek K, Sill H, Knuutila S, Kolitz JE, Archer KJ, Caligiuri MA, Bloomfield CD, de La Chapelle A: BAALC, the human member of a novel mammalian neuroectoderm gene lineage, is implicated in hematopoiesis and acute leukemia. Proc Natl Acad Sci U S A 2001, 98:13901-13906.

80. Satoskar AA, Tanner SM, Weinstein M, Qualman SJ, de la Chapelle A: Baalc a marker of mesoderm and muscle. Gene Expr Patterns 2005, 5:463-473.

81. Baldus CD, Tanner SM, Kusewitt DF, Liyanarachchi S, Choi C, Caligiuri MA, Bloomfield CD, de la Chapelle A: BAALC, a novel marker of human hematopoietic progenitor cells. Exp Hematol 2003, 31:1051-1056.

82. Sommer F, Kobuch K, Brandl F, Wild B, Framme C, Weiser B, Tessmar J, Gabel VP, Blunk T, Goepferich A: Ascorbic acid modulates proliferation and extracellular matrix accumulation of hyalocytes. Tissue Eng 2007, 13:1281-1289.

83. Dehne T, Schenk R, Perka C, Morawietz L, Pruss A, Sittinger M, Kaps C, Ringe J: Gene expression profiling of primary human articular chondrocytes in high-density micromasses reveals patterns of recovery, maintenance, re- and dedifferentiation. Gene 2010, 462:8-17.

84. Weber GL, Parat MO, Binder ZA, Gallia GL, Riggins GJ: Abrogation of PIK3CA or PIK3R1 reduces proliferation, migration, and invasion in glioblastoma multiforme cells. Oncotarget 2011, 2:833-849.

85. Keita M, Bachvarova M, Morin C, Plante M, Gregoire J, Renaud MC, Sebastianelli A, Trinh XB, Bachvarov D: The RUNX1 transcription factor is 
expressed in serous epithelial ovarian carcinoma and contributes to cell proliferation, migration and invasion. Cell Cycle 2013, 12:972-986.

86. Kahler RA, Yingst SM, Hoeppner LH, Jensen ED, Krawczak D, Oxford JT, Westendorf JJ: Collagen 11a1 is indirectly activated by lymphocyte enhancer-binding factor 1 (Lef1) and negatively regulates osteoblast maturation. Matrix Biol 2008, 27:330-338.

87. Granchi D, Ochoa G, Leonardi E, Devescovi V, Baglio SR, Osaba L, Baldini N, Ciapetti G: Gene expression patterns related to osteogenic differentiation of bone marrow-derived mesenchymal stem cells during ex vivo expansion. Tissue Eng Part C Methods 2010, 16:511-524.

88. Ciapetti G, Granchi D, Devescovi V, Baglio SR, Leonardi E, Martini D, Jurado MJ, Olalde B, Armentano I, Kenny JM, Walboomers FX, Alava JI, Baldini N: enhancing osteoconduction of PLLA-based nanocomposite scaffolds for bone regeneration using different biomimetic signals to MSCs. Int J Mol Sci 2012, 13:2439-2458.

89. Madeira A, da Silva CL, dos Santos F, Camafeita E, Cabral JM, Sa-Correia I: Human mesenchymal stem cell expression program upon extended ex-vivo cultivation, as revealed by 2 -DE-based quantitative proteomics. PLoS One 2012, 7:e43523.

90. Mendicino M, Bailey AM, Wonnacott K, Puri RK, Bauer SR: MSC-based product characterization for clinical trials: an FDA perspective. Cell Stem Cell 2014, 14:141-145.

doi: $10.1186 /$ scrt448

Cite this article as: Bellayr et al:: Gene markers of cellular aging in human multipotent stromal cells in culture. Stem Cell Research \& Therapy 2014 5:59.

\section{Submit your next manuscript to BioMed Central and take full advantage of:}

- Convenient online submission

- Thorough peer review

- No space constraints or color figure charges

- Immediate publication on acceptance

- Inclusion in PubMed, CAS, Scopus and Google Scholar

- Research which is freely available for redistribution 